NASA/TM-2003-212171

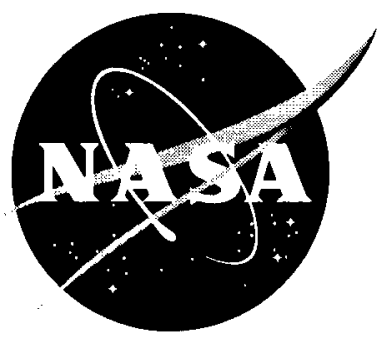

\title{
Thermal/Mechanical Response of a Polymer Matrix Composite at Cryogenic Temperatures
}

Karen S. Whitley and Thomas S. Gates

Langley Research Center, Hampton, Virginia

National Aeronautics and

Space Administration

Langley Research Center

Hampton, Virginia 23681-2199 
Available from:

NASA Center for AeroSpace Information (CASI)

National Technical Information Service (NTIS)

7121 Standard Drive

Hanover, MD 21076-1320

(301) 621-0390

5285 Port Royal Road

Springfield, VA 22161-2171

(703) 605-6000 


\section{Abstract}

In order for polymeric-matrix composites to be considered for use as structural materials in the next generation of space transportation systems, the mechanical behavior of these materials at cryogenic temperatures must be investigated. This paper presents experimental data on the residual mechanical properties of a carbon-fiber polymeric composite, IM7/PETI-5, both before and after aging. Both tension and compression modulus and strength were measured at room temperature, $-196^{\circ} \mathrm{C}$, and $-269^{\circ} \mathrm{C}$ on five different laminate configurations. One set of specimens was aged isothermally for 576 hours at $-184^{\circ} \mathrm{C}$ in an unconstrained state. Another set of corresponding specimens was aged under constant uniaxial strain for 576 hours at $-184^{\circ} \mathrm{C}$. Based on the experimental data presented, it is shown that trends in stiffness and strength that result from changes in temperature are not always smooth and consistent. Moreover, it is shown that loading mode and direction are significant for both stiffness and strength, and aging at cryogenic temperature while under load can alter the mechanical properties of pristine, un-aged laminates made of IM7/PETI-5 material.

\section{Introduction}

The National Aeronautics and Space Administration (NASA) has recently initiated the Space Launch Initiative (SLI) program that will, in part, advance some of the key technologies required for the next generation of launch vehicles. This next generation of space transportation systems may require both reusable launch vehicles (RLV's) and expendable launch vehicles (ELV's) to satisfy mission requirements. One of the key technologies identified for RLV's and ELV's has been the reduction in structural weight through the use of advanced materials and manufacturing methods. This reduction in structural weight must be tempered against the increased demands on performance, damage tolerance, and lifetime durability. One potential source for structural weight reduction is the replacement of traditional metallic cryogenic-fuel tanks with polymericmatrix-composite (PMC) tanks. The interest in design of polymeric-composite, cryogenic-fuel tanks for launch vehicles goes back several years and includes research associated with the National Aerospace Plane (NASP), single-stage-to-orbit (SSTO) vehicles [1], [2] and other launch vehicle applications [3]. For internal and external tanks, design of the tank may take the form of externally stiffened shells of PMC material or thin-walled sandwich shells constructed with a lightweight core and PMC facesheets. Regardless of the design, the PMC-based tanks will be required to safely carry pressure and flight loads and operate over temperatures that may range from $-250^{\circ} \mathrm{C}$ to $+120^{\circ} \mathrm{C}$. From a durability perspective, the primary performance criteria of the PMC material is to retain mechanical properties within allowable limits over the life time of the tank, while minimizing loss of cryogenic fuel due to permeation or leakage through the tank wall.

Aside from their use in space launch vehicles, there have been very few applications of PMC's as structural materials in cryogenic environments. Consequently, a review of the available literature provides a limited amount of experimental data on the mechanical properties of polymers or PMC's operating at cryogenic temperatures. For amorphous and crystalline polymeric materials, Perepechko [4] provides details on a number of non-mechanical properties that include thermal expansion, thermal conductivity, as well as, viscoelastic or dynamical mechanical properties. From these studies, it is clear that many of the polymer properties are not 
linear with respect to temperature over a range from room temperature to approximately absolute zero. In the work by Pannkoke [5], fatigue tests were performed on unidirectional thermoplastic composites at $-196^{\circ} \mathrm{C}$. The fatigue strength at $10^{6}$ cycles was found to be only $60 \%$ of the static strength. In this work, it was recognized that large thermal stresses degraded the fatigue performance. In a series of articles by Ahlborn [6], [7], static tests, and thermally cycled, and mechanically cycled tests were performed on unidirectional and cross-ply thermoplastic composites. Isothermal tests were performed at $23^{\circ} \mathrm{C},-196^{\circ} \mathrm{C}$, and $-269^{\circ} \mathrm{C}$ and cyclic thermal tests were performed between $-196^{\circ} \mathrm{C}$ and $23^{\circ} \mathrm{C}$. Strength, damage, and fatigue life were measured for all test conditions. He found that the matrix-dominated properties, shear and transverse tension, were largely related to the effects of temperature on static strength. As the temperature decreased, increases in matrix-dominated strength, could be offset by the development of thermal-stress-induced cracks. As in previous studies, the fatigue life was reduced as the test temperature was decreased.

More recently, a compilation of test data for several PMC material systems [8] indicated that tensile modulus, tensile strength, and compressive strength all generally increased as the test temperature was decreased from $23^{\circ} \mathrm{C}$ to $-269^{\circ} \mathrm{C}$. Once again, it was found that thermal stresses had a large influence on behavior and that the sensitivity of matrix-dominated properties to temperature can be used to help explain the stress-strain response of laminated composites. Of these matrix-dominated properties, transverse ply strength appears to play a critical role in the development and growth of residual stress-induced matrix cracks. Schoeppner [9] recently investigated the range of thermomechanical loading over which steady-state matrix cracking is likely to occur. Shimoda [10] has performed additional studies related to matrix crack development in PMC's due to cryogenic-temperature exposure.

It is recognized that a broad spectrum of factors influence the mechanical properties of PMC's including material selection, composite fabrication and handling, aging or preconditioning, specimen preparation, laminate ply lay-up, test procedures, etc. The present study focuses on test temperature, preconditioning methods, and laminate configuration as the primary test variables. It is expected that by focusing on those three variables the results of this study will aid in the development of future material qualification methods and design verification testing. Toward that purpose, this paper provides experimental results and test methods developed from a series of thermal/mechanical tests. The selected test conditions represent a range of exposure times, loads and temperatures similar to those experienced during the lifetime of a liquidhydrogen fuel tank.

In particular, this paper first presents a description of the material system, IM7/PETI-5, and the material characterization test-plan, including a description of the experimental methods that were used for tension and compression testing at room temperature and cryogenic temperatures. Also presented, are the techniques used to precondition the IM7/PETI-5 material, followed by details on acquiring the residual property measurements. In addition, residual-stress analysis is used to evaluate thermal stresses as a function of ply lay-up, test temperature, and preconditioning. Results of the residual stiffness and strength are also evaluated as a function of ply lay-up, test temperature, and pre-conditioning. Finally, photographs of the fracture and edge surfaces are shown, and discussed. 


\section{Material System}

The PMC material used in this study, IM7/PETI-5, consisted of a continuous high-strength, intermediate-modulus, carbon fiber in a thermoplastic polyimide matrix. All test materials were laminated composites fabricated at the NASA Langley Research Center. These composite panels consisted of $[0]_{12}$ and $[90]_{12}$ unidirectional laminates, $[ \pm 25]_{35}$ and $[ \pm 45]_{3 s}$ angle-ply laminates, and a 13-ply laminate given by $\left[45 / 90_{3} /-45 / \overline{0}_{3}\right]_{\mathrm{s}}$. The bar notation over the 0 indicates that the $0_{3}$ ply group spans the mid-plane of the laminate. Figure 1 provides a schematic illustrating the $0^{\circ}$ ply and the $90^{\circ}$ fiber directions relative to the specimen dimensions. These lay-ups were chosen to provide basic lamina-level material constants and for the case of the $[ \pm 25]_{3 \mathrm{~s}}$ and $\left[45 / 90_{3} /-45 / \overline{0}_{3}\right]_{S}$ laminates, to be representative of a composite wall in a typical cryogenic-propellant tank. For a cryogenic tank, the orientation of the $0^{\circ}$ in the $\left[45 / 90_{3} /-45 / \overline{0}_{3}\right]_{s}$ laminate would be along the longitudinal axis of the tank.

All composite panels were fabricated by hand lay-up. The bagging and cure processes employed are consistent with standard practices. Specifically, a full vacuum was applied to each bagged panel during the entire cure cycle. The cycle started with a ramp to $260^{\circ} \mathrm{C}$, at $5^{\circ} \mathrm{C}$ /minute. After a 1 -hour hold at $260^{\circ} \mathrm{C}$, the autoclave was pressurized to $1480 \mathrm{kPa}$ at 170 $\mathrm{kPa} /$ minute while the temperature was increased to $370^{\circ} \mathrm{C}$ at $5^{\circ} \mathrm{C} /$ minute. Then, the temperature was held at $370^{\circ} \mathrm{C}$ for 1 hour, and the pressure was maintained until the temperature cooled to $38^{\circ} \mathrm{C}$. After curing, through-transmission, ultrasonic inspection of the laminates indicated that there were no significant internal anomalies in any of the panels. The glass transition temperature $\left(\mathrm{T}_{\mathrm{g}}\right)$ of the as-received composite material was $267^{\circ} \mathrm{C}$, as measured by the peak in the Tan $\delta$ curve of tests run in a dynamic mechanical analysis (DMA) test [11].

\section{Material Characterization}

The material characterization test plan consisted of two phases. The first phase addressed material aging where the material was subjected to long- term exposure at cryogenic temperature in either an unloaded (unconstrained) or statically loaded state. The second phase was residual property characterization of pristine and aged specimens at three temperatures $\left(23^{\circ},-196^{\circ}\right.$, and $-269^{\circ} \mathrm{C}$ ). This second phase provided fundamental material properties and an understanding of material behavior as a function of prior aging conditions and test temperatures. The complete test matrix, including the phase-one aging conditions and the phase-two residual property tests, are shown in table 1.

All tests were conducted on coupon-type specimens that were cut from larger panels prior to aging. Three replicates of each condition were used to generate the test data. A schematic of the tension-test coupon is presented in figure 1. The 254-mm-long tension coupons were mounted in the test set-up such that $63 \mathrm{~mm}$ of each end were gripped between two serrated face-plates, leaving a $128-\mathrm{mm}$ test section. The face-plates were clamped together by using six hex-head bolts, which were torqued to $61 \mathrm{~N}$-m with a hand-held torque wrench. The tensile coupons tested at room temperature were $152.4 \mathrm{~mm}$ long, and $38.1 \mathrm{~mm}$ of each end were mounted in hydraulic wedge grips, leaving a $76.2-\mathrm{mm}$ test section.

The general set of guidelines used for the tension test included ASTM D3039-76 and the Suppliers of Advanced Composite Materials (SACMA) SRM 4R-94 test method [12]. The tensile modulus was calculated by using ASTM D3039-76 and a linear regression least-squares 
curve fit of the stress-strain data in the linear region of the stress-strain curve. The linear region of the stress-strain curve was most commonly defined as being between $1000 \mu \varepsilon$ and $3000 \mu \varepsilon$ for all test conditions and specimen ply lay-ups.

Because an existing end-loaded compression fixture, developed by Northrup Grumman, had been successfully used for previous compression testing of IM7/PETI-5, for the NASA High Speed Research Program [13], it was selected as the fixture to be used for the compression testing in this study. A schematic of the compression coupon is presented in figure 2 . The gauged coupon is placed in the center cut-out section of the compression test fixture, as shown in figure 3(a). A side view of the assembled fixture is shown in figure 3(b). The compression tests were performed by using the SACMA recommended method, SRM 1R-94 [14], and the ASTM D695 references as guides. The compressive strength and modulus were calculated according to the method described in ASTM D695, by calculating the slope of the tangent to the initial linear portion of the stress-strain curve. In most cases, the linear region of the stress-strain curve from the compression test was defined as being between $1000 \mu \varepsilon$ and $2000 \mu \varepsilon$ for all test conditions and specimen ply lay-ups.

\section{Test phase one - Material aging}

Another unique test fixture, also developed under the NASA High Speed Research Program, was used to produce a constant tensile-strain condition for half of the total number of specimens used during the aging phase. Several fixtures, like the one shown in figure 4 , were constructed of Invar material (coefficient of thermal expansion (CTE) $=1.4 \mu \mathrm{mm} / \mathrm{mm}-{ }^{\circ} \mathrm{C}$ ) and could accommodate two rectangular specimens. The high stiffness of the fixture relative to the test specimen and the low CTE of the Invar material ensured a constant-strain condition during the entire aging period. The ability of the test-fixture to maintain a constant strain within a specimen was verified by applying a pre-load to a gauged specimen mounted in the fixture, and monitoring the strain while aging at $-184^{\circ} \mathrm{C}$. Each specimen was individually preloaded to the desired strain level by compressing a series of spring-type washers that react against the frame to put the specimen into tension. The washers were compressed by turning an adjacent nut with a handheld wrench, while the strain in the specimen was monitored with a longitudinal extensometer mounted on the specimen. The preload strain levels, given in table 1, were selected to be approximately $50 \%$ of the not-aged room-temperature failure strain. A corresponding set of specimens was aged in an unconstrained condition. The constant-strain fixtures with specimens and the corresponding unconstrained specimens were placed into a large cryo-chamber that maintained a constant temperature of $-184^{\circ} \mathrm{C}$ for an aging time of 576 hours.

\section{Test phase two - Residual properties}

In phase two of the test program, residual strength and stiffness of all three sets of specimens (pristine, aged without load, aged with load) were measured at room temperature $\left(24^{\circ} \mathrm{C}\right)$, $-196^{\circ} \mathrm{C}$, and $-269^{\circ} \mathrm{C}$. All residual-property tests were performed with a servo-hydraulic test machine, using a displacement rate of $1.27 \mathrm{~mm} / \mathrm{min}$. The isothermal cryogenic test conditions at $-196^{\circ} \mathrm{C}$ and $-269^{\circ} \mathrm{C}$ were achieved by immersing the test specimen and load introduction apparatus into liquid nitrogen or liquid helium, respectively. In order to reach thermal 
equilibrium, the specimen stayed immersed in a constant level of the cryogen for at least 15 minutes prior to mechanical loading.

Stress in the test specimens was calculated by using load, as measured by the test-machine load cell, divided by the original cross section of the specimen. Strain in the tensile-test specimens was measured by using a combination of a cryogenic-rated axial extensometer (MTS model 634.11F-21) and bonded electrical-resistance strain gages (Measurements Group WK-00250BG-350). Strain in the room-temperature compressive-test specimens was measured by using strain gages, Measurements Group CEA-06-125WT-350, and the compression specimens tested at cryogenic temperatures used Measurements Group WK-06-120WT-350 gages. Strain gage selection was based on considerations discussed in the report [15], "Strain Gage Selection," such as material CTE, static-load test conditions, isothermal test temperatures, and gage availability. The WK-series gages are self-temperature-compensating to correct for thermal drift. Placement of these sensors on the tensile specimens is shown in figure 1 , and placement on the compression specimen is shown in figure 2. All the strain gages were bonded in a back-to-back configuration.

Prior to aging, representative samples were polished along one edge. Sections $(2.6 \times 1.3 \mathrm{~cm})$ were potted in a clear epoxy mold and were then circulated in an automated polishing wheel at 150 rpm's with an applied weight of 5 pounds per specimen. Consecutive grades of grit paper $(600,800,1200$ grit) were used for the polishing. The specimens received a final polish with a solution of silica alumina suspension fluid. The polished specimen edges were examined for damage (microcracks, delaminations) using optical microscopy, and photomicrographs were taken to establish the baseline condition. After aging, but prior to the destructive residual tests, visual examination of all lay-ups was again performed to determine if the exposure conditions generated any microcracks, damage, or change in surface morphology. Photomicrographs representative of the specimen's edge before and after aging are shown in figure 5.

\section{Residual-Stress Analysis}

The previous studies cited herein indicate that thermal stresses alone may degrade laminate performance. For thermal loading, stresses are induced at the ply level by mismatches in expansion or contraction of ply constituents and by constraining effects caused by adjacent plies that prevent a free relative expansion or contraction. The residual stresses in any ply can be calculated by using classical laminated plate theory [16]. In general, for a unidirectional laminate under plane stress, the constitutive relationship is given by

$$
\left\{\begin{array}{l}
\sigma_{11} \\
\sigma_{22} \\
\sigma_{12}
\end{array}\right\}=\left[\begin{array}{ccc}
Q_{11} & Q_{12} & 0 \\
Q_{12} & Q_{22} & 0 \\
0 & 0 & Q_{66}
\end{array}\right]\left(\left\{\begin{array}{c}
\varepsilon_{11} \\
\varepsilon_{22} \\
\gamma_{12}
\end{array}\right\}-\left\{\begin{array}{c}
\varepsilon_{11}^{T} \\
\varepsilon_{22}^{T} \\
\gamma_{12}^{T}
\end{array}\right\}\right)
$$

where $\sigma_{\mathrm{ij}}$ are the normal stress components in the principal material directions, $\varepsilon_{\mathrm{ij}}$ are the normal strains in the principal material directions, and $Q_{\mathrm{ij}}$ are the reduced stiffness coefficients. In this equation, the subscripts" 1 " and " 2 " denote the fiber direction and inplane direction perpendicular 
to the fiber, respectively. The thermal strains, in the principal material directions, $\varepsilon_{i j}^{T}$, are calculated using

$$
\left\{\begin{array}{l}
\varepsilon_{11}^{T} \\
\varepsilon_{22}^{r} \\
\gamma_{12}^{T}
\end{array}\right\}=\left\{\begin{array}{l}
\alpha_{1} \\
\alpha_{2} \\
0
\end{array}\right\} \Delta T
$$

The thermal strains are proportional to the temperature change, $\Delta T$, which is the temperature difference between the test condition and the stress-free condition at cure. The constants of proportionality are the coefficients of thermal expansion (CTE), $\alpha_{1}$ and $\alpha_{2}$. The thermal shear strain, $\gamma_{12}^{T}$, is zero because an orthotropic material only exhibits dilation along its principal material coordinate directions, with a change in temperature. Clearly, from equation (2) it is apparent that for large values of $\Delta T$, which occur at cryogenic temperatures, the magnitude of the thermally induced strains is highly dependent on the material CTE values. In particular, nonlinear behavior of the CTE with respect to temperature, as illustrated in table 2 of reference [17], may result in residual thermal stresses that also vary in a nonlinear manner with respect to temperature. To illustrate this effect, CTE values and material properties given in table 3 were used with classical laminated plate theory to predict the maximum transverse ply stress, $\sigma_{22}$, as a function of laminate stacking sequence, test temperature, and laminate preconditioning. The results of these calculations are given in table 4 . It should be noted that CTE values of pristine material were used for all conditions and the stress-free temperature was assumed to be the glass transition temperature of IM7/PETI-5. With respect to temperature, table 4 indicates that the trend for the not-aged condition is for the transverse stress to increase with a decrease in temperature. However, both of the isothermal-aged conditions predict the largest stress $\left(\sigma_{22}\right)$ to occur at the intermediate temperature, $-196^{\circ} \mathrm{C}$. With respect to ply lay-up, the highly constrained $\left[45 / 90_{3} /-45 / \overline{0}_{3}\right]_{S}$ laminate is predicted to have the highest stress at any given temperature. However, the $[ \pm 45]_{3 S}$ angle-ply laminate is predicted to have stress magnitudes close to those predicted for the $\left[45 / 90_{3} /-45 / \overline{0}_{3}\right]_{S}$ laminate. With respect to preconditioning, no clear trends are evident from a residual-stress analysis.

\section{Results and Discussion}

In this section of the present paper, elastic modulus and residual strength results are presented for laminates with $[0]_{12},[ \pm 25]_{3 \mathrm{~s}},\left[45 / 90_{3} /-45 / \overline{0}_{3}\right]_{s},[90]_{12}$, and $[ \pm 45]_{3 \mathrm{~s}}$, ply stacking sequences. Tables 3 and 5 contain the tensile and compressive elastic modulus, respectively, at the three different test temperatures, for each lay-up, and for each aging condition. Each value in the table represents the average of three replicates, along with the standard deviation. The lamina inplane moduli values, $E_{1}$ and $E_{2}$, were calculated directly from stress-strain behavior of the $[0]_{12}$ and $[90]_{12}$ unidirectional laminates, respectively. The laminate effective modulus value $\mathrm{E}_{\mathrm{x}}$ of the $[ \pm 25]_{3 \mathrm{~S}}$ and $\left[45 / 90_{3} /-45 / \overline{0}_{3}\right]_{\mathrm{S}}$ laminates was calculated from the laminate stress-strain behavior. The lamina in-plane shear modulus $G_{12}$ was calculated indirectly from the stress-strain behavior of the $[ \pm 45]_{3 \mathrm{~S}}$ laminates by using the equation, 


$$
G_{12}=\frac{E_{x}}{2\left(1+v_{x y}\right)}
$$

where $v_{\mathrm{xy}}$ is the laminate Poisson's ratio and $E_{x}$ is the laminate longitudinal modulus. The form of equation (3) is customarily associated with isotropic materials, however for the special case of a $[ \pm 45]_{S}$ laminate subjected to axial loading, the shear modulus can be calculated by using this equation. (See reference [18]).

Measured laminate tensile and compressive strength values are listed in tables 6 and 7 , respectively, along with the associated standard deviation. Failure was defined as the point of complete loss of load-carrying capability during the test. Due to the nonlinear nature of the stress-strain behavior in the $[ \pm 45]_{3 S}$ laminates, their tensile strength was defined as the initial point of deviation from the nearly horizontal portion of the stress-strain curve. Normalized tensile modulus and strength of the $[0]_{12},[ \pm 45]_{3 S}$, and $\left[45 / 90_{3} /-45 / \overline{0}_{3}\right]_{S}$ laminates are presented in figures 6-11 and normalized compressive modulus and strength are presented in figures 12-17. Both modulus and strength values have been normalized against the corresponding results for the not-aged condition tested at room temperature for each laminate.

\section{Effect of Temperature on Modulus and Strength}

By examining the results from specimens subjected to the not-aged test condition, the effects of temperature on tensile modulus and strength were found. The fiber-dominated $[0]_{12}$ laminate experienced a decrease in both the modulus and strength due to testing at cryogenic temperatures, with up to a $35 \%$ decrease in strength for the $-196^{\circ} \mathrm{C}$ case. Conversely, the shear modulus and longitudinal strength of the matrix-dominated $[ \pm 45]_{3 S}$ laminate increased as the temperature decreased. The shear modulus increased by as much as $35 \%$ and the strength by as much as $50 \%$ when tested at $-269^{\circ} \mathrm{C}$. The transverse modulus $\left(\mathrm{E}_{2}\right)$ showed a slight decline at cryogenic temperatures while the transverse strength dropped by approximately $70 \%$ when the temperature was reduced to $-269^{\circ} \mathrm{C}$. The tensile modulus and strength of the not-aged $\left[45 / 90_{3} /-\right.$ $\left.45 / \overline{0}_{3}\right]_{S}$ laminates decreased by nearly $20 \%$ at $-196^{\circ} \mathrm{C}$, with some reverse in this decline as the temperature was lowered to $-269^{\circ} \mathrm{C}$. The $[ \pm 25]_{3 \mathrm{~S}}$ laminates showed little sensitivity in modulus or strength to cryogenic temperature.

The compressive modulus and strength increased for all the laminates that were tested at cryogenic temperatures. In most cases, the highest modulus and strength occurred at the lowest test temperature $\left(-269^{\circ} \mathrm{C}\right)$. Of all the laminates tested, the [90] ${ }_{12}$ laminates experienced the greatest increase $(67 \%)$ in strength while the $[ \pm 45]_{3 s}$ laminates experienced the greatest increase $(57 \%)$ in modulus at cryogenic temperatures.

\section{Effect of Aging on Modulus and Strength}

To determine the effects of aging, the panels subjected to the not-aged condition were compared to the corresponding panels subjected to the aged-without-load and the aged-with-load conditions. The results show that, in general, aging had very little effect on the tensile modulus of the fiber-dominated $[0]_{12}$ laminate. Aging did cause a slight increase in tensile strength for the $[0]_{12}$ laminate, with the most significant change occurring when tested at $-269^{\circ} \mathrm{C}$ after aging with 
load. In contrast, aging did not significantly affect the shear modulus or the longitudinal strength of the matrix-dominated $[ \pm 45]_{3 S}$ laminate.

For the $\left[45 / 90_{3} /-45 / \overline{0}_{3}\right]_{S}$ laminate, aging increased the modulus. The $\left[45 / 903_{3} /-45 / \overline{0}_{3}\right]_{S}$ laminate that was aged with load, experienced the largest increase $(18 \%)$ in modulus, which occurred at $-269^{\circ} \mathrm{C}$. Aging also increased the strength of the $\left[45 / 90_{3} /-45 / \overline{0}_{3}\right]_{\mathrm{S}}$ laminate, with the most significant increase occurring for the aged-with-load condition, where the strength increased relative to the baseline strength by $21 \%$ at $-196^{\circ} \mathrm{C}$ and $11 \%$ at $-269^{\circ} \mathrm{C}$. In general, aging decreased the modulus of the $[ \pm 25]_{35}$ laminate and had little effect on the laminate strength. From the limited data for the $[90]_{12}$ laminate, it appears that aging had little effect on the transverse modulus and the strength.

As expected, the standard deviation in strength measurements was more significant than the standard deviation associated with modulus measurements. In part, large standard deviations in the strength values can be attributed the fact that strength is defined by a single value, whereas modulus is an averaged value, given by the slope of the stress-strain curve. Strength in laminated composites is also more sensitive to processing, handling, and test-parameter variability.

The compressive modulus and strength of the $[0]_{12}$ laminate were not greatly influenced by aging. The matrix-dominated $[ \pm 45]_{3 \mathrm{~S}}$ laminate showed a decrease in modulus and strength due to aging in most cases, and in general, the modulus decreased more than the strength. The compressive modulus of the $\left[45 / 90_{3} /-45 / \overline{0}_{3}\right]_{\mathrm{S}}$ laminate tended to decrease after aging. However, the compressive strength of the $\left[45 / 90_{3} /-45 / \overline{0}_{3}\right]_{S}$ laminate increased due to aging. The greatest increase $(88 \%)$ occurred at $-269^{\circ} \mathrm{C}$ after aging with load, however, the standard deviation associated with those strength values was quite high. The room-temperature modulus and strength of the $[ \pm 25]_{3 \mathrm{~S}}$ laminate were unaffected by aging. However, at $-196^{\circ} \mathrm{C}$ both the modulus and the strength increased due to aging. The $[90]_{12}$ laminate was not significantly affected by aging.

\section{Fracture Surfaces}

The fracture surfaces of each failed specimen were examined for any distinguishing features that could be attributed to test temperature or aging conditions. It was observed that aging did not produce any distinguishing characteristics in the fracture surfaces of the tensile specimens. The greatest distinction in the appearance was observed when comparing the fracture surfaces of the room-temperature-test specimens with those of the cryogenic-temperature-test specimens. However, there were no discernable differences between the specimens tested at $-196^{\circ} \mathrm{C}$ and the specimens tested at $-269^{\circ} \mathrm{C}$.

The fracture surface of the $\left[45 / 90_{3} /-45 / \overline{0}_{3}\right]_{\mathrm{S}}$ laminates tested at room temperature and $-196^{\circ} \mathrm{C}$ are shown in figures 18 and 19 , respectively. The fractured edge of the $\left[45 / 90_{3} /-45 / \overline{0}_{3}\right]_{S}$ laminates tested at room temperature appeared more jagged, such that the $\pm 45^{\circ}$ laminae were more apparent. The $\left[45 / 90_{3} /-45 / \overline{0}_{3}\right]_{s}$ laminates tested at $-196^{\circ} \mathrm{C}$ failed such that the fracture surface was nearly perpendicular to the direction of the applied load. The $[ \pm 25]_{3 S}$ laminates tested at room temperature (figure 20) displayed irregular fracture surfaces, whereas the $[ \pm 25]_{3 \mathrm{~S}}$ laminates tested at $-196^{\circ} \mathrm{C}$ displayed a very clean-cut failure at a $25^{\circ}$ angle that is shown in figure 21 . All the $[0]_{12}$ laminates failed by splitting along the $0^{\circ}$ direction. The $[0]_{12}$ laminates tested at room temperature displayed a catastrophic splintering as shown in figure 22 , whereas 
the $[0]_{12}$ laminates (figure 23 ) tested at $-196^{\circ} \mathrm{C}$, were characterized by only a few splits through the thickness. In general, the failure of the $\left[45 / 90_{3} /-45 / \overline{0}_{3}\right]_{\mathrm{S}},[ \pm 25]_{3 \mathrm{~S}}$, and the $[0]_{12}$ laminates at cryogenic temperatures could be described as "clean breaks," as opposed to the irregular fragmented breaks that occurred at room temperature. The clean breaks indicate that a more brittle fracture occurred at cryogenic temperatures, and the irregular breaks indicate that a more ductile fracture occurred at room temperature. There was no difference in the fracture surface of the $[90]_{12}$ laminates, which all failed straight across the width of the specimen in the $90^{\circ}$ direction, regardless of the test temperature. Due to the nonlinear stress-strain behavior of the $[ \pm 45]_{3 \mathrm{~S}}$ laminate, loading to the point of fracture did not always occur.

The fracture surfaces of the specimens tested in compression did not show any differences due to test temperature or aging conditions, possibly due to the fact that the test fixture enclosed most of the compression coupon. However, each set of laminate configurations displayed unique failure characteristics, as expected. In all cases, failure occurred contiguously above or below the strain-gage section. The $[0]_{12}$-laminate compression failures did not split along the length, as in the tension tests. Instead, the fracture surface could be described as having a short broom-like appearance along the failed edge (figure 24). The [90 $]_{12}$ laminates failed with a clean-cut, beveled edge across the width (figure 25 ). The $[ \pm 25]_{3 \mathrm{~S}}$ laminates failed sharply along a $\pm 25^{\circ}$ angle ply and failure may have propagated from any one of the four corners of the specimen (figure 26). The $\left[45 / 90_{3} /-45 / \overline{0}_{3}\right]_{S}$ laminate, failed straight across the width of the specimen, with the fracture surface having a crushed appearance (figure 27 ).

\section{Edge Surface Morphology}

Optical examination of surface morphology was intended to provide data on the initiation and growth of any damage that occurred during specimen aging. Photomicrographs of the specimen's polished edges taken during this study are shown in figure 5 . The photos in the first column are for the not-aged material, the second column are specimens that have been aged without load, and the third column are specimens that have been aged with load. Very few microcracks or similar damage were observed before or after aging in any of the lay-ups. However, the surface morphology shows some definite degradation along the exposed edges after aging without load, and it appears that further surface degradation occured after aging with load. This degradation occurred in all lay-ups and can be described as pitting in the matrix regions.

\section{$\underline{\text { Summary and Conclusions }}$}

Five different laminates made of IM7/PETI-5 were evaluated for tensile and compressive strength and stiffness at room temperature and at two cryogenic temperatures. The effects of laminate configuration, test temperature, and preconditioning or aging were investigated. Aging consisted of 576 hours of exposure in a $-184^{\circ} \mathrm{C}$ environment, both with and without constantstrain mechanical load. Specimens were also examined for evidence of damage or microcracking before and after aging.

Examination of the basic laminate properties such as strength and stiffness, in the longitudinal and transverse directions, indicates that cryogenic temperatures can have an appreciable 
influence on behavior, as expected, but unexpected trends can occur. For example, the tensiontest data show that the longitudinal and transverse stiffness and strength decreased as the test temperature decreased. Conversely, the tensile shear modulus and strength increased as the temperature decreased. For tension loading, some of the laminate stacking sequences, such as $\left[45 / 90_{3} /-45 / \overline{0}_{3}\right]_{S}$ and $[ \pm 25]_{3 \mathrm{~S}}$, were influenced less by a reduction in temperature, than the other laminates. However, the $\left[45 / 90_{3} /-45 / \overline{0}_{3}\right]_{\mathrm{S}}$ laminate was more sensitive to cryogenic temperatures than the $[ \pm 25]_{3 S}$ laminate. For compression loads, exposure to cryogenic temperatures produced an increase in both the modulus and strength of all the laminates. The greatest increase in compressive strength occurred for the $[90]_{12}$ laminates and the greatest increase in modulus occurred for the $[ \pm 45]_{3 \mathrm{~S}}$ laminates.

Based on lamination theory, residual-stress calculations indicate that the transverse tensile ply stresses, associated with matrix cracking, can be quite high at cryogenic test temperatures. The $[ \pm 25]_{3 \mathrm{~S}}$ and $\left[45 / 90_{3} /-45 / \overline{0}_{3}\right]_{\mathrm{S}}$ laminates were predicted to have the highest values of residual stress, which is important because these transverse residual stresses may reduce the strength and stiffness of the laminates by accelerating the initiation, growth, and accumulation of transverse microcracks in a ply.

Aging the material at a constant cryogenic temperature caused changes in the strength and stiffness, compared to the corresponding values for the not-aged or as-received condition. In general, it appears that this type of aging will increase both the tensile strength and stiffness, particularly in the $[ \pm 45]_{3 s},[90]_{12}$, and $\left[45 / 90_{3} /-45 / \overline{0}_{3}\right]_{S}$ laminates. Of particular interest, is the fact that isothermal-cryogenic aging while at a constant strain condition produced some additional increase in strength and stiffness, as compared to aging in an unconstrained condition. The aging tends to decrease the compressive strength and stiffness in the $[ \pm 45]_{3 s},[90]_{12}$, and the $[0]_{12}$ laminates. For the IM7/PETI-5 material, aging at cryogenic temperatures also produces degradation in the matrix material along the exposed edges. This degradation may have an adverse influence on residual strength due to an increase in possible failure initiation sites.

The aging did not influence the fracture surface characteristics. Cryogenic temperatures affected the fracture surfaces of only the tensile specimens. In general, the fracture surfaces from the room-temperature tensile tests appeared catastrophic, having irregular breaks, whereas the specimens tested at cryogenic temperatures exhibited clean breaks with a more regular appearance. The differences in the fracture surfaces of the tensile specimens were attributed to the ductility of the matrix material at room temperature verses the brittle nature of the matrix at low temperatures.

Overall, the results of the present study show that the trends for changes in stiffness and strength with changes in temperature are not always as expected, indicating that tests should be run at several temperature levels. In addition, the loading mode and direction are significant for both stiffness and strength characterization. Likewise, aging or long-term exposure at cryogenic temperature while under load can alter the mechanical properties of the as-received laminate, implying that design values should take into account thermomechanical exposure over the lifetime of the structure. 


\section{Acknowledgements}

The authors would like to express their thanks to Lisa Hawks, Everitt Brown, and Ed Townsley of NASA Langley Research Center for their technical support.

\section{References}

1. Morino, Y., Ishikawa, T., Aoki, T., Kumaza, H., Hayashi, Y., "Feasibility Study of CFRP Material Application to the Cryogenic Propellant Tank of Reusable Launch Vehicles in," 6th Japan International SAMPE Symposium, Japan, 1999, pp. 1127-1130.

2. Robinson, M. J., "Composite Structures on the DC-XA Reusable Launch Vehicle," 28th International SAMPE Technical Conference, Seattle, Washington, 1996.

3. Callaghan, M. T., "Use of resin composites for cryogenic tankage," Cryogenics, Vol. 31, No. 4, 1991, pp. 282-287.

4. Perepechko, I., Low-Temperature Properties of Polymers, Mir Publishers, Moscow, 1997.

5. Pannkoke, K., Wagner, H. J., "Fatigue properties of unidirectional carbon fiber composites at cryogenic temperatures," Cryogenics, Vol. 31, No. 4, 1991, pp. 248-251.

6. Ahlborn, K., "Durability of carbon fibre reinforced plastics with thermoplastic matrices under cyclic mechanical and cyclic thermal loads at cryogenic temperatures," Cryogenics, Vol. 31, No. 4, 1991, pp. 257-260.

7. Ahlborn, K., "Cryogenic mechanical response of carbon fibre reinforced plastics with thermoplastic matrices to quasi-static loads," Cryogenics, Vol. 31, No. 4, 1991, pp. 252 256.

8. Schutz, J. B., "Properties of composite materials for cryogenic applications," Cryogenics, Vol. 38, No. 1, 1998, pp. 3-12.

9. Schoeppner, G. A., Kim, R., Donaldson, S. L., "Steady State Cracking of PMC's at Cryogenic Temperatures," 42nd AIAA/ASME/ASCE/AHS/ASC Structural Dynamics and Materials Conference, Seattle, WA, AIAA-2001-1216, 2001.

10. Shimoda, T., "Study of CFRP Application to the Cryogenic Propellant Tank of Reusable Launch Vehicle," 42nd AIAA/ASME/ASCE/AHS/ASC Structural Dynamics and Materials Conference, Seattle, WA, AIAA-2001-1598, 2001.

11. Kampf, G., Characterization of Plastics by Physical Methods, Experimental Techniques, and Practical Application, Hanser, Munich, 1986. 
12. SACMA, "SACMA Recommended Test Method for Tensile Properties of Oriented Fiber-Resin Composites" SRM 4R-94 (Composites Fabricators Association, 1999).

13. National Research Council, Ed., U.S. Supersonic Commercial Aircraft, National Academy Press, Washington, D.C., 1997.

14. SACMA, "SACMA Recommended Test Method for Compressive Properties of Oriented Fiber-Resin Composites" SRM IR-94 (Composites Fabricators Association, 1999).

15. Groups, V. M., “Strain Gage Selection” TN 505 (Vishay Intertechnology, Inc., 1999).

16. Jones, R. M., Mechanics of Composite Materials, Scripta Book Company, Washington, D.C., 1975.

17. Johnson, T. F., Gates, T. S., "High Temperature Polyimide Materials in Extreme Temperature Environments," 42nd AIAA/ASME/ASCE/AHS/ASC Structural Dynamics, and Materials Conference, Seattle, WA, AIAA-2001-1214, 2001.

18. Herakovich, C. T., Mechanics of Fibrous Composites, John Wiley \& Sons, Inc., New York, 1998. 
Table 1. Test matrix illustrating the residual test temperature and aging condition for each type of laminate

\begin{tabular}{cccc}
\hline \multirow{2}{*}{$\begin{array}{c}\text { Test } \\
\text { temperature } \\
\left({ }^{\circ} \mathrm{C}\right)\end{array}$} & No load & $\begin{array}{c}\text { Static load } \\
(3000 \mu \varepsilon)\end{array}$ & $\begin{array}{c}\text { Static load } \\
(4000 \mu \varepsilon)\end{array}$ \\
\cline { 2 - 4 } & $\begin{array}{c}{[0]_{12},[90]_{12},} \\
{[ \pm 45]_{3 \mathrm{~s}},[ \pm 25]_{3 \mathrm{~s}},} \\
{\left[45 / 90_{3} /-45 / \overline{0}_{3}\right]_{\mathrm{s}}}\end{array}$ & $\begin{array}{c}{[ \pm 45]_{12},} \\
{[0]_{12}}\end{array}$ & $\begin{array}{c}{[ \pm 25]_{3 \mathrm{~s}},} \\
{\left[45 / 90_{3} /-45 / \overline{0}_{3}\right]_{\mathrm{s}}}\end{array}$ \\
\hline \multirow{4}{*}{$\begin{array}{c}{[0]_{12},[90]_{12},} \\
{[ \pm 45]_{3 \mathrm{~s}},[ \pm 25]_{3 \mathrm{~s}},}\end{array}$} & {$[ \pm 45]_{12}$,} & {$[ \pm 25]_{3 \mathrm{~s}}$,} \\
\hline & {$\left[45 / 90_{3} /-45 / \overline{0}_{3}\right]_{\mathrm{s}}$} & {$[0]_{12}$} & {$\left[45 / 90_{3} /-45 / \overline{0}_{3}\right]_{\mathrm{s}}$} \\
\hline & {$[0]_{12},[90]_{12}$,} & {$[ \pm 45]_{12}$,} & {$[ \pm 25]_{3 \mathrm{~s}}$,} \\
-196 & {$[ \pm 45]_{3 \mathrm{~s}},[ \pm 25]_{3 \mathrm{~s}}$,} & {$[0]_{12}$} & {$\left[45 / 90_{3} /-45 / \overline{0}_{3}\right]_{\mathrm{s}}$} \\
\hline
\end{tabular}

Table 2. Coefficients of thermal expansion for not-aged IM7/PETI-5 material system

\begin{tabular}{ccc}
\hline Temp & \multicolumn{2}{c}{$\mu \mathrm{mm} / \mathrm{mm}-{ }^{\circ} \mathrm{C}$} \\
\cline { 2 - 3 }$\left({ }^{\circ} \mathrm{C}\right)$ & $\alpha_{1}$ & $\alpha_{2}$ \\
\cline { 2 - 3 } 24 & -1.30 & 19.45 \\
-196 & -1.49 & 20.05 \\
-273 & -2.77 & 18.46 \\
\hline
\end{tabular}


Table 3. Measured tensile elastic modulus values

\begin{tabular}{lccccc}
\hline $\begin{array}{c}\text { Specimen ply } \\
\text { lay - up }\end{array}$ & $\begin{array}{c}\text { Temp } \\
{ }^{\circ} \mathrm{C}\end{array}$ & $\begin{array}{c}\text { Material } \\
\text { property }\end{array}$ & $\begin{array}{c}\text { Not aged } \\
\text { modulus (GPa) } \\
\pm \text { Std dev. }\end{array}$ & $\begin{array}{c}\text { Aged without load } \\
\text { modulus (GPa) } \\
\pm \text { Std dev. }\end{array}$ & $\begin{array}{c}\text { Aged with load } \\
\text { modulus (GPa) } \\
\pm \text { Std dev. }\end{array}$ \\
\hline$[0]_{12}$ & 24 & $\mathrm{E}_{1}$ & $157.6 \pm 9.3$ & $153.6 \pm 5.9$ & $147.2 \pm 2.6$ \\
{$[0]_{12}$} & -196 & $\mathrm{E}_{1}$ & $151.6 \pm 2.2$ & $146.3 \pm 11.5$ & $149.2 \pm 1.9$ \\
{$[0]_{12}$} & -269 & $\mathrm{E}_{1}$ & $145.1 \pm 7.4$ & $143.0 \pm 8.8$ & $158.6 \pm 20.8$ \\
{$[ \pm 25]_{3 \mathrm{~S}}$} & 24 & $\mathrm{E}_{\mathrm{x}}$ & $71.9 \pm 1.0$ & $70.3 \pm 1.6$ & $59.8 \pm 2.6$ \\
{$[ \pm 25]_{3 \mathrm{~S}}$} & -196 & $\mathrm{E}_{\mathrm{x}}$ & $75.7 \pm 0.8$ & $63.8 \pm 8.5$ & $71.5 \pm 3.0$ \\
{$[ \pm 25]_{3 \mathrm{~S}}$} & -269 & $\mathrm{E}_{\mathrm{x}}$ & $73.1 \pm 3.7$ & 69.4 & $65.6 \pm 12.2$ \\
{$\left[45 / 90_{3} /-45 / \overline{0}_{3}\right]_{\mathrm{S}}$} & 24 & $\mathrm{E}_{\mathrm{x}}$ & $50.7 \pm 1.0$ & $46.7 \pm 4.3$ & $51.0 \pm 1.1$ \\
{$\left[45 / 90_{3} /-45 / \overline{0}_{3}\right]_{\mathrm{S}}$} & -196 & $\mathrm{E}_{\mathrm{x}}$ & $40.6 \pm 5.9$ & $48.0 \pm 1.8$ & $48.6 \pm 3.0$ \\
{$\left[45 / 90_{3} /-45 / \overline{0}_{3}\right]_{\mathrm{S}}$} & -269 & $\mathrm{E}_{\mathrm{x}}$ & $43.8 \pm 1.9$ & $44.3 \pm 3.9$ & $52.1 \pm 1.3$ \\
{$[90]_{12}$} & 24 & $\mathrm{E}_{2}$ & $8.7 \pm 0.1$ & $8.6 \pm 0.1$ & $\mathrm{NA}$ \\
{$[90]_{12}$} & -196 & $\mathrm{E}_{2}$ & $7.5 \pm 0.1$ & $9.5 \pm 2.0$ & $9.6 \pm 0.1$ \\
{$[90]_{12}$} & -269 & $\mathrm{E}_{2}$ & $7.8 \pm 1.2$ & $7.1 \pm 0.8$ & $\mathrm{NA}$ \\
{$[ \pm 45]_{3 \mathrm{~S}}$} & 24 & $\mathrm{G}_{12}$ & $4.6 \pm 0.4$ & $5.0 \pm 0.1$ & $5.8 \pm 0.2$ \\
{$[ \pm 45]_{3 \mathrm{~S}}$} & -196 & $\mathrm{G}_{12}$ & $5.8 \pm 0.1$ & $6.2 \pm 0.1$ & $6.0 \pm 0.2$ \\
{$[ \pm 45]_{3 \mathrm{~S}}$} & -269 & $\mathrm{G}_{12}$ & $6.2 \pm 0.2$ & $5.5 \pm 0.9$ & $6.1 \pm 0.3$ \\
\hline$[\mathrm{NA}=\mathrm{nOt}$ & & & & & \\
\hline
\end{tabular}

(NA = not available)

* Only one specimen tested. 
Table 4. Calculated maximum transverse ply stress, $\sigma_{22}$, for thermal loading only

\begin{tabular}{cccccc}
\hline & & \multicolumn{4}{c}{ Maximum transverse ply stress (MPa) } \\
\cline { 3 - 6 } Precondition & Temp & {$[0]_{12}$} & {$[ \pm 25]_{3 \mathrm{~s}}$} & $\begin{array}{c}{\left[45 / 90_{3} /\right.} \\
-\end{array}$ & {$[ \pm 45]_{3 \mathrm{~s}}$} \\
& $\left({ }^{\circ} \mathrm{C}\right)$ & & & $\left.-45 / \overline{0}_{3}\right]_{\mathrm{s}}$ & \\
\hline \multirow{3}{*}{ Not aged } & 24 & 0.0 & 18.2 & 41.3 & 40.6 \\
& -196 & 0.0 & 37.7 & 70.9 & 69.7 \\
& -269 & 0.0 & 45.7 & 83.7 & 82.3 \\
\hline \multirow{3}{*}{ Iso-aged without } & 24 & 0.0 & 18.9 & 40.8 & 40.1 \\
& -196 & 0.0 & 43.6 & 88.3 & 86.5 \\
& -269 & 0.0 & 40.8 & 76.5 & 75.3 \\
\hline \multirow{2}{*}{ Iso-aged with load } & 24 & 0.0 & 20.4 & 40.7 & 39.9 \\
& -196 & 0.0 & 43.1 & 89.3 & 87.5 \\
& -269 & 0.0 & 42.9 & 76.9 & 75.8 \\
\hline
\end{tabular}

Table 5. Measured compressive elastic modulus values

\begin{tabular}{lccccc}
\hline $\begin{array}{c}\text { Specimen ply } \\
\text { lay - up }\end{array}$ & $\begin{array}{c}\text { Temp } \\
{ }^{\circ} \mathrm{C}\end{array}$ & $\begin{array}{c}\text { Material } \\
\text { property }\end{array}$ & $\begin{array}{c}\text { Not aged } \\
\text { modulus (GPa) } \\
\pm \text { Std dev }\end{array}$ & $\begin{array}{c}\text { Aged without load } \\
\text { modulus (GPa) } \\
\pm \text { Std dev. }\end{array}$ & $\begin{array}{c}\text { Aged with load } \\
\text { modulus (GPa) } \\
\pm \text { Std dev. }\end{array}$ \\
\hline$[0]_{12}$ & 24 & $\mathrm{E}_{1}$ & $135.2 \pm 1.1$ & $139.0 \pm 3$ & $129.9 \pm 4.8$ \\
{$[0]_{12}$} & -196 & $\mathrm{E}_{1}$ & $142.0 \pm 15.0$ & $154.0 \pm 5.9$ & $147.9 \pm 5.5$ \\
{$[0]_{12}$} & -269 & $\mathrm{E}_{1}$ & $146.9 \pm 11.1$ & $143.1 \pm 6.0$ & $139.9 \pm 11.4$ \\
{$[ \pm 25]_{3 \mathrm{~S}}$} & 24 & $\mathrm{E}_{\mathrm{x}}$ & $63.2 \pm 5.7$ & $60.0 \pm 4.1$ & $62.8 \pm 3.1$ \\
{$[ \pm 25]_{3 \mathrm{~S}}$} & -196 & $\mathrm{E}_{\mathrm{x}}$ & $64.1 \pm 7.5$ & $72.1 \pm 8.0$ & $72.6 \pm 2.5$ \\
{$[ \pm 25]_{3 \mathrm{~S}}$} & -269 & $\mathrm{E}_{\mathrm{x}}$ & $77.5 \pm 17.5$ & $77.3 \pm 9.4$ & $69.5 \pm 1.7$ \\
{$\left[45 / 90_{3} /-45 / \overline{0}_{3}\right]_{\mathrm{S}}$} & 24 & $\mathrm{E}_{\mathrm{x}}$ & $44.3 \pm 5.1$ & $46.3 \pm 0.9$ & $40.7 \pm 7.6$ \\
{$\left[45 / 90_{3} /-45 / \overline{0}_{3}\right]_{\mathrm{S}}$} & -196 & $\mathrm{E}_{\mathrm{x}}$ & $60.6 \pm 7.3$ & $50.8 \pm 4.8$ & $52.2 \pm 7.0$ \\
{$\left[45 / 90_{3} /-45 / \overline{0}_{3}\right]_{\mathrm{S}}$} & -269 & $\mathrm{E}_{\mathrm{x}}$ & $51.2 \pm 4.2$ & $47.6 \pm 1.1$ & $53.7 \pm 5.0$ \\
{$[90]_{12}$} & 24 & $\mathrm{E}_{2}$ & $11.6 \pm 1.7$ & $12.1 \pm 0.5$ & $\mathrm{NA}$ \\
{$[90]_{12}$} & -196 & $\mathrm{E}_{2}$ & $11.9 \pm 1.1$ & $11.1 \pm 0.5$ & $\mathrm{NA}$ \\
{$[90]_{12}$} & -269 & $\mathrm{E}_{2}$ & $12.8 \pm 1.1$ & $12.2 \pm 01.6$ & $\mathrm{NA}$ \\
{$[ \pm 45]_{3 \mathrm{~S}}$} & 24 & $\mathrm{G}_{12}$ & $4.8 \pm 2.5$ & $5.3 \pm 0.5$ & $4.3 \pm 0.1$ \\
{$[ \pm 45]_{3 \mathrm{~S}}$} & -196 & $\mathrm{G}_{12}$ & $6.7 \pm 0.8$ & $5.4 \pm 0.5$ & $6.0 \pm 1.2$ \\
{$[ \pm 45]_{3 \mathrm{~S}}$} & -269 & $\mathrm{G}_{12}$ & $7.6 \pm 3.0$ & $5.8 \pm 0.3$ & $7.0 \pm 2.0$ \\
\hline
\end{tabular}

(NA $=$ not available) 
Table 6. Measured tensile strength values

\begin{tabular}{ccccc}
\hline $\begin{array}{c}\text { Specimen ply } \\
\text { lay- up }\end{array}$ & $\begin{array}{c}\text { Temp } \\
{ }^{\circ} \mathrm{C}\end{array}$ & $\begin{array}{c}\text { Not aged } \\
\text { strength (MPa) } \\
\pm \text { Std dev. }\end{array}$ & $\begin{array}{c}\text { Aged without load } \\
\text { strength (MPa) } \\
\pm \text { Std dev. }\end{array}$ & $\begin{array}{c}\text { Aged with load } \\
\text { strength (MPa) } \\
\pm \text { Std dev. }\end{array}$ \\
\hline$[0]_{12}$ & 24 & $1939.8 \pm 276.3$ & $1864.8 \pm 42.42$ & $1847.8 \pm 49.4$ \\
{$[0]_{12}$} & -196 & $1277.9 \pm 207.5$ & $1567.7 \pm 39.0$ & $1536.1 \pm 125.8$ \\
{$[0]_{12}$} & -269 & $1495.2 \pm 326.2$ & $1451.0 \pm 275.1$ & $1771.4 \pm 186.3$ \\
{$[ \pm 25]_{35}$} & 24 & $1132.2 \pm 76.8$ & $1265.9 \pm 57.8$ & $954.9 \pm 83.8$ \\
{$[ \pm 25]_{3 S}$} & -196 & $911.6 \pm 49.5$ & $902.4 \pm 208.1$ & $1119.5 \pm 51.4$ \\
{$[ \pm 25]_{3 \mathrm{~S}}$} & -269 & $1130.7 \pm 15.0$ & $1113.6 *$ & $1024.4 \pm 209.2$ \\
{$\left[45 / 90_{3} /-45 / \overline{0}_{3}\right]_{\mathrm{S}}$} & 24 & $711.0 \pm 14.0$ & $699.9 \pm 67.0$ & $842.6 \pm 37.9$ \\
{$\left[45 / 900_{3} /-45 / \overline{0}_{3}\right]_{\mathrm{S}}$} & -196 & $585.4 \pm 118.7$ & $747.9 \pm 57.1$ & $872.4 \pm 39.7$ \\
{$\left[45 / 900_{3} /-45 / \overline{0}_{3}\right]_{\mathrm{S}}$} & -269 & $656.5 \pm 47.6$ & $731.8 \pm 64.4$ & $806.1 \pm 2.1$ \\
{$[90]_{12}$} & 24 & $46.7 \pm 1.9$ & $46.6 \pm 3.0$ & $\mathrm{NA}$ \\
{$[90]_{12}$} & -196 & $21.0 \pm 3.5$ & $23.5 \pm 30.1$ & $63.1 \pm 4.9$ \\
{$[90]_{12}$} & -269 & $17.5 \pm 3.9$ & $11.3 \pm 4.7$ & $\mathrm{NA}$ \\
{$[ \pm 45]_{3 \mathrm{~S}}$} & 24 & $162.7 \pm 2.3$ & $165.0 \pm 0.5$ & $182.0 \pm 4.3$ \\
{$[ \pm 45]_{3 \mathrm{~S}}$} & -196 & $241.6 \pm 3.7$ & $249.0 \pm 3.0$ & $245.4 \pm 7.7$ \\
{$[ \pm 45]_{35}$} & -269 & $255.9 \pm 8.2$ & $257.0 \pm 11.9$ & $257.0 \pm 4.7$ \\
\hline
\end{tabular}

(NA = not available) Note: Tensile strength of $[ \pm 45]_{3 \mathrm{~S}}$ was defined as the initial point of deviation from the tangent of the nearly horizontal slope of the stress strain curve.

*Only one specimen tested. 
Table 7. Measured compressive strength values

\begin{tabular}{ccccc}
\hline $\begin{array}{c}\text { Specimen ply } \\
\text { lay- up }\end{array}$ & $\begin{array}{c}\text { Temp } \\
{ }^{\circ} \mathrm{C}\end{array}$ & $\begin{array}{c}\text { Not aged } \\
\text { strength (MPa) } \\
\pm \text { Std dev. }\end{array}$ & $\begin{array}{c}\text { Aged without load } \\
\text { strength (MPa) } \\
\pm \text { Std dev. }\end{array}$ & $\begin{array}{c}\text { Aged with load } \\
\text { strength (MPa) } \\
\pm \text { Std dev. }\end{array}$ \\
\hline$[0]_{12}$ & 24 & $857.5 \pm 52.5$ & $856.2 \pm 102.4$ & $817.4 \pm 74.2$ \\
{$[0]_{12}$} & -196 & $1124.8 \pm 127.6$ & $1167.2 \pm 60.9$ & $1115.2 \pm 66.2$ \\
{$[0]_{12}$} & -269 & $1193.5 \pm 100.8$ & $1234.7 \pm 44.6$ & $1156.1 \pm 61.0$ \\
{$[ \pm 25]_{35}$} & 24 & $502.9 \pm 65.7$ & $467.7 \pm 37.2$ & $524.8 \pm 43.4$ \\
{$[ \pm 25]_{35}$} & -196 & $604.2 \pm 9.6$ & $709.5 \pm 0.3$ & $685.6 \pm 87.2$ \\
{$[ \pm 25]_{3 \mathrm{~S}}$} & -269 & $714.8 \pm 132.7$ & $749.4 \pm 27.2$ & $571.2 \pm 61.5$ \\
{$\left[45 / 90_{3} /-45 / \overline{0}_{3}\right]_{S}$} & 24 & $473.3 \pm 121.8$ & $432.6 \pm 10.2$ & $530.6 \pm 107.5$ \\
{$\left[45 / 90_{3} /-45 / \overline{0}_{3}\right]_{\mathrm{S}}$} & -196 & $375.7 \pm 130.1$ & $554.3 \pm 29.8$ & $709.5 \pm 89.2$ \\
{$\left[45 / 90_{3} /-45 / \overline{0}_{3}\right]_{\mathrm{S}}$} & -269 & $572.2 \pm 28.6$ & $619.1 \pm 11.9$ & $723.0 \pm 113.4$ \\
{$[90]_{12}$} & 24 & $220.0 \pm 10.0$ & $280.0 \pm 11.5$ & $\mathrm{NA}$ \\
{$[90]_{12}$} & -196 & $293.7 \pm 16.1$ & $273.7 \pm 52.7$ & $\mathrm{NA}$ \\
{$[90]_{12}$} & -269 & $367.6 \pm 35.1$ & $301.9 \pm 21.8$ & $\mathrm{NA}$ \\
{$[ \pm 45]_{3 \mathrm{~S}}$} & 24 & $426.7 \pm 27.7$ & $398.3 \pm 26.4$ & $364.8 \pm 12.2$ \\
{$[ \pm 45]_{3 \mathrm{~S}}$} & -196 & $536.8 \pm 73.3$ & $511.0 \pm 57.1$ & $530.5 \pm 21.4$ \\
{$[ \pm 45]_{3 \mathrm{~S}}$} & -269 & $578.1 \pm 13.8$ & $569.5 \pm 10.38$ & $454.6 \pm 98.0$ \\
\hline
\end{tabular}

(NA = not available) 


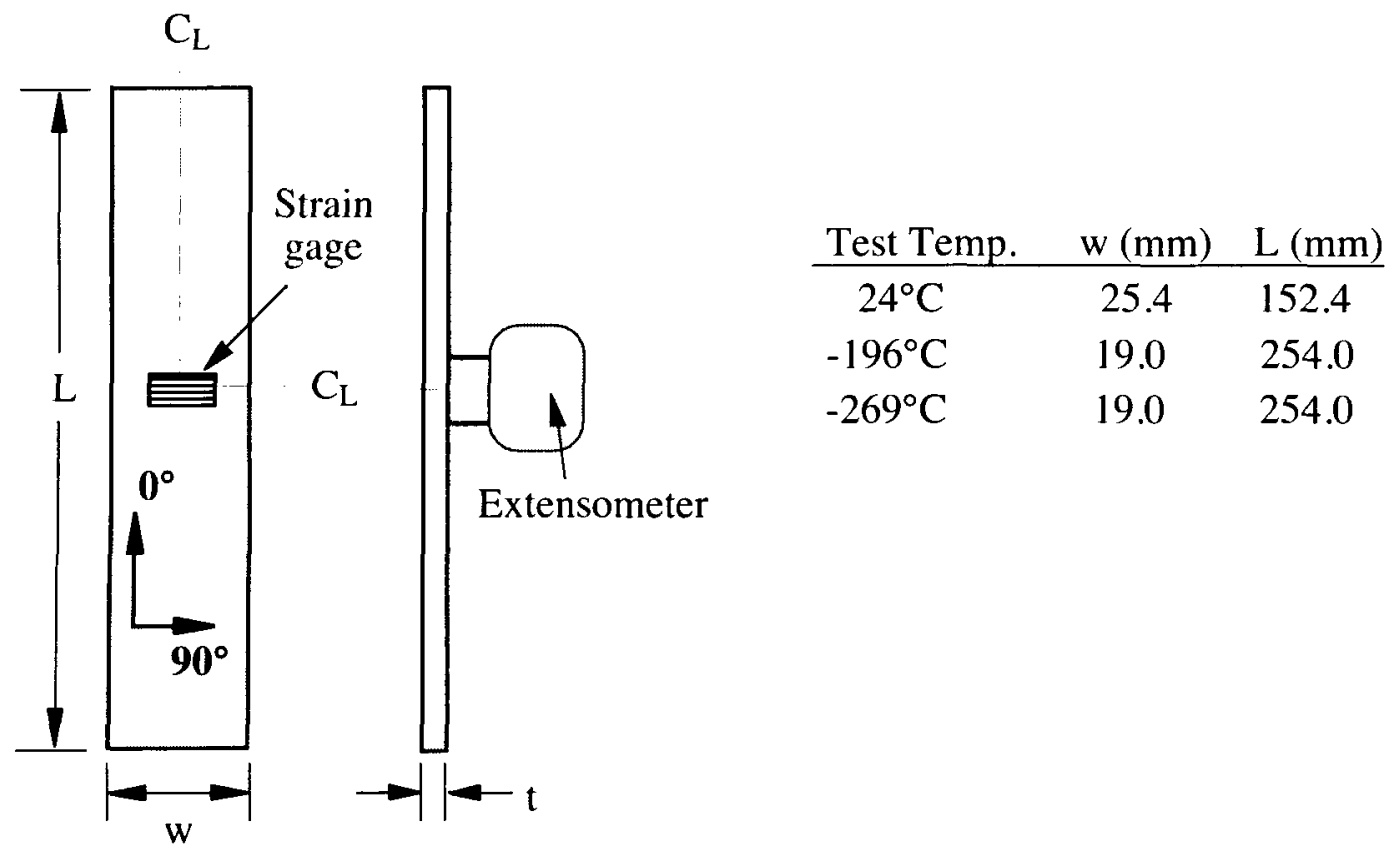

Figure 1. Tensile specimen schematic. Axial strain gages are mounted back-to-back on specimen.

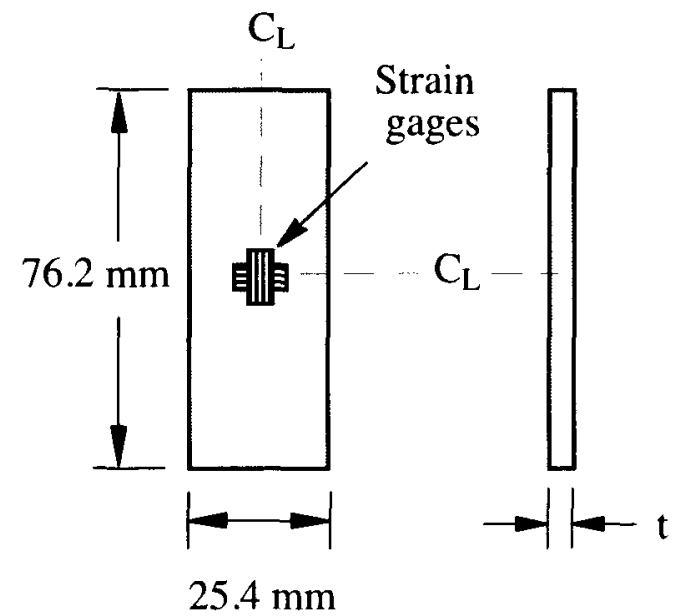

Figure 2. Compression specimen schematic. Stacked strain gages are mounted back-to-back on specimen. 

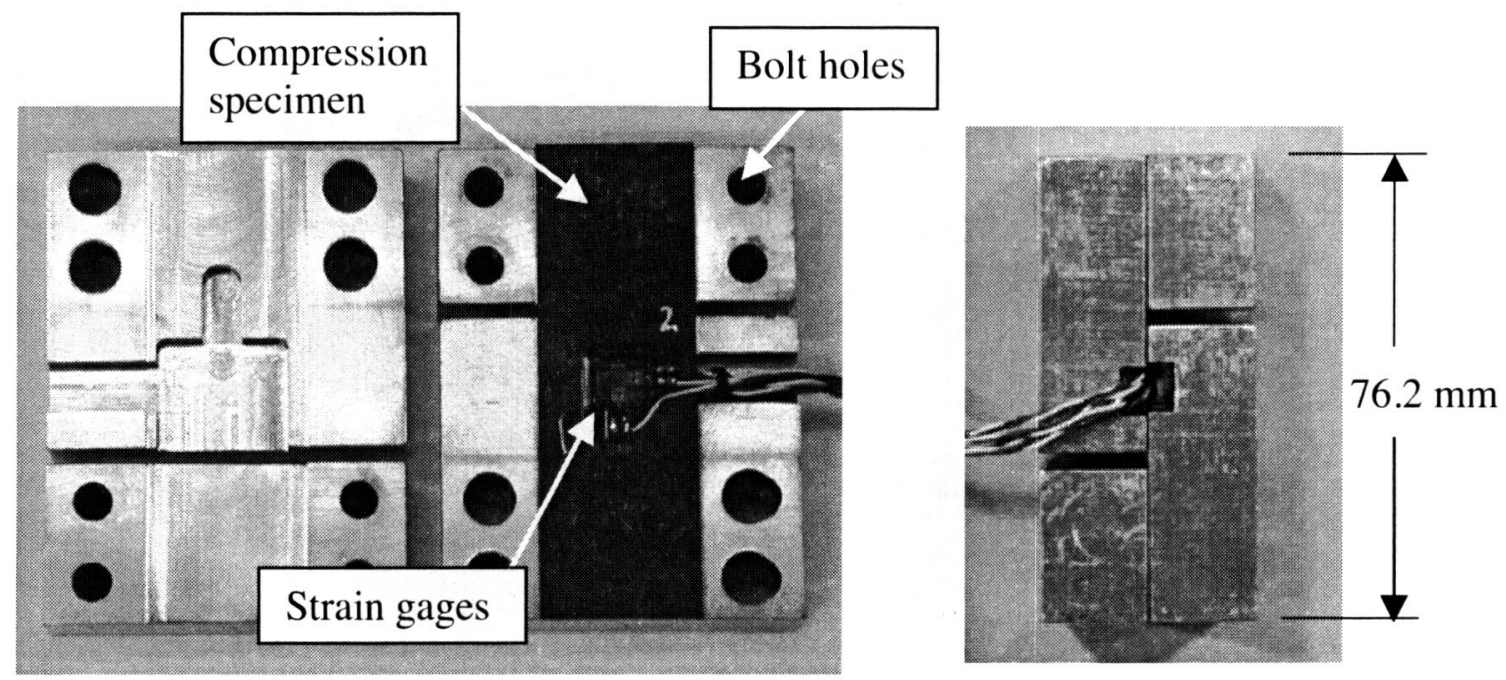

a) open view

b) side view

Figure 3. Compression-test fixture.

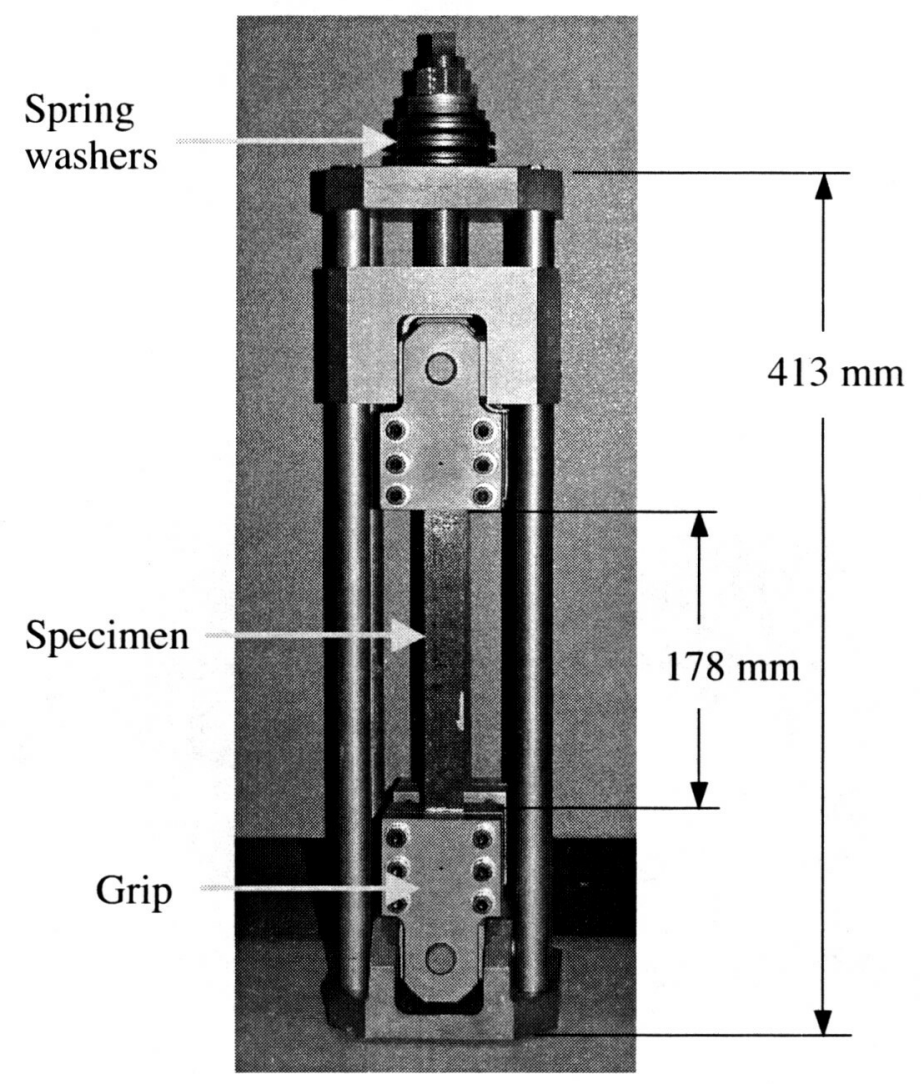

Figure 4. Constant-strain fixture. 

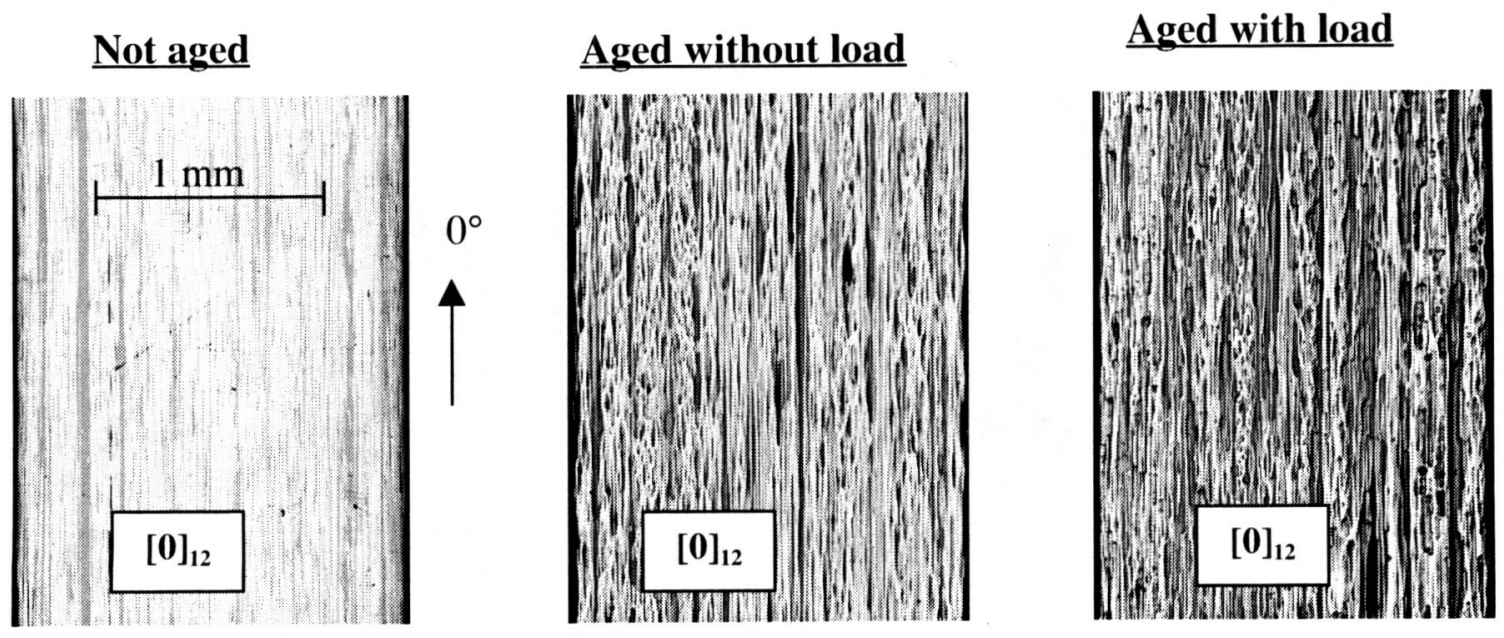

(a) $[0]_{12}$ laminate
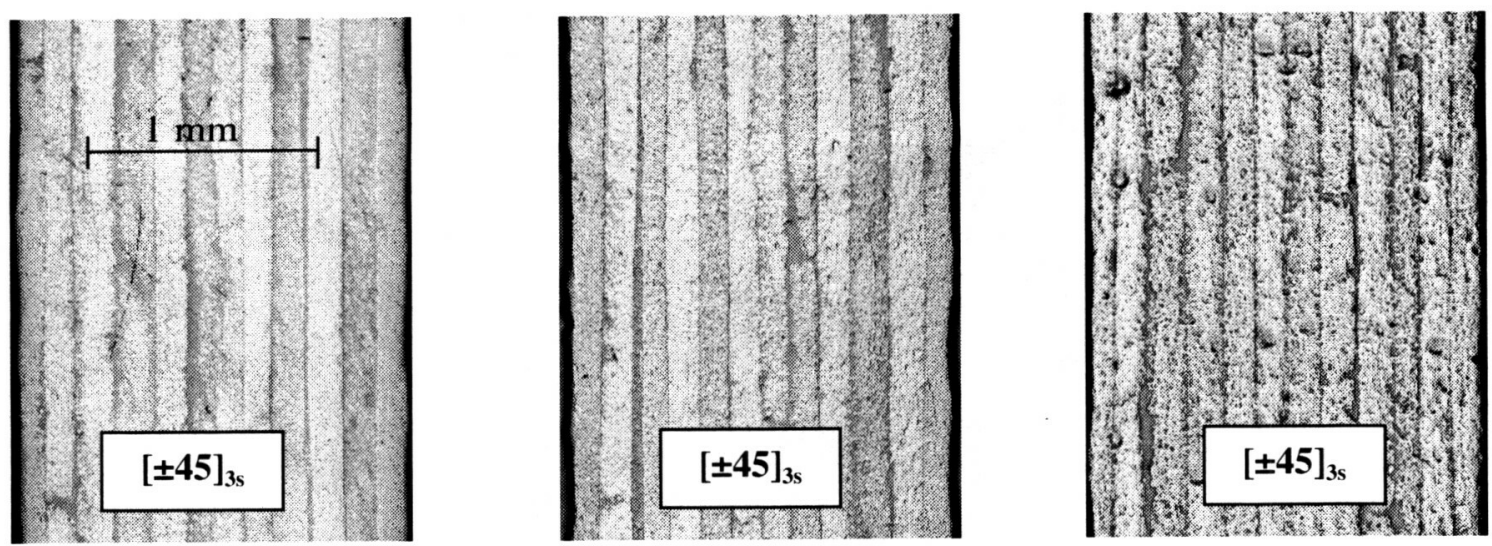

(b) $[ \pm 45]_{3 \mathrm{~S}}$ laminate
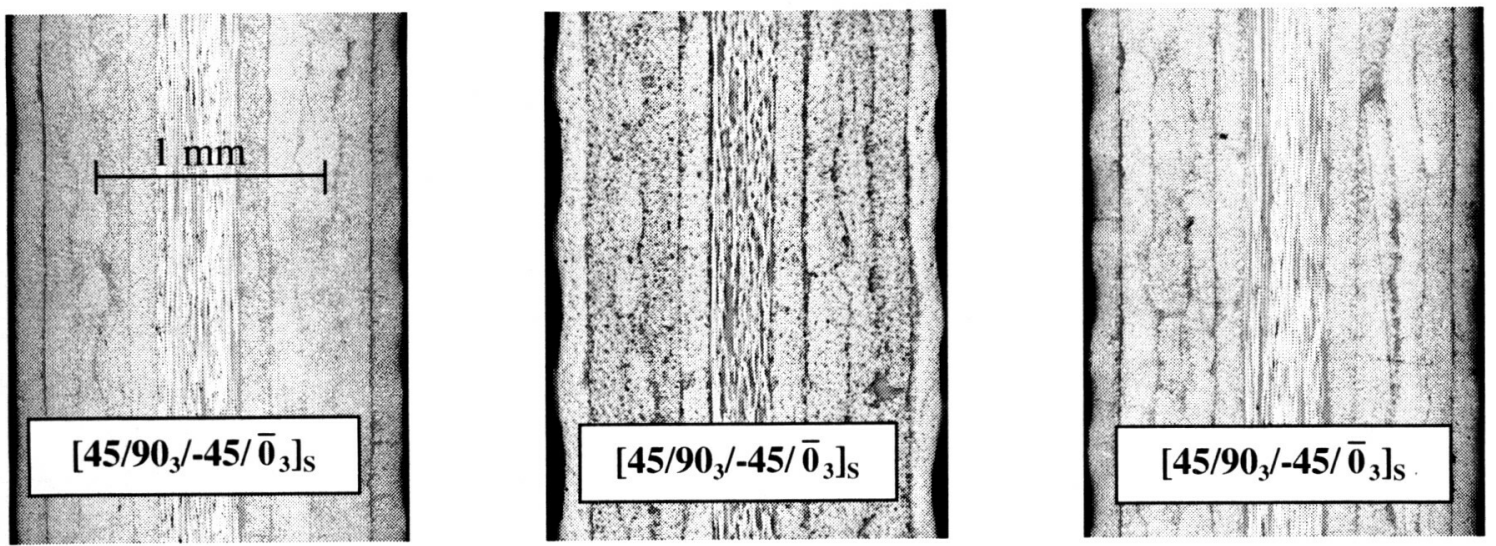

(c) $\left[45 / 90_{3} /-45 / \overline{0}_{3}\right]_{\mathrm{S}}$ laminate

Figure 5. Photomicrographs of specimen's edge prior to aging, after aging without load, and after aging with load. 


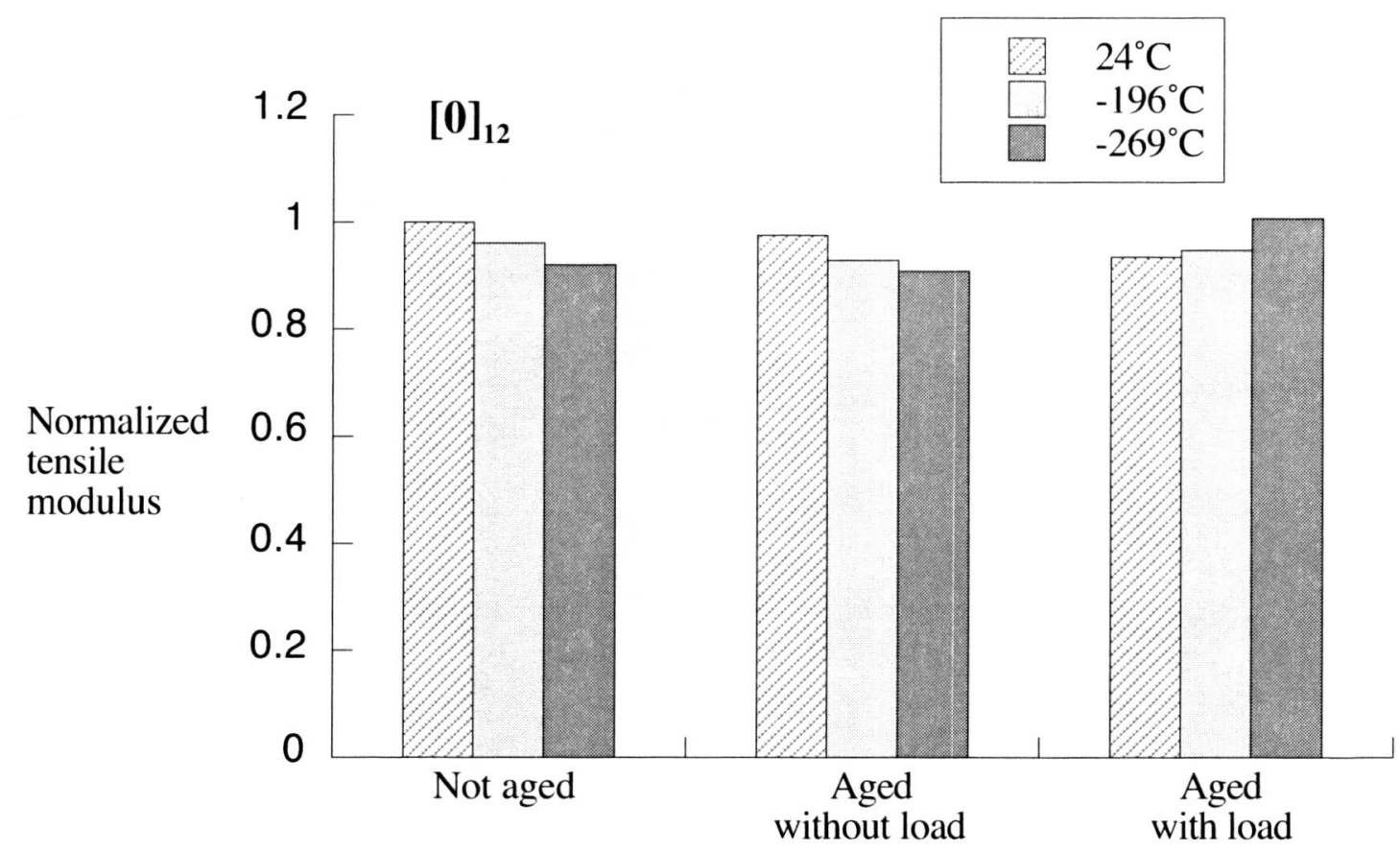

Figure 6. Tensile modulus of $[0]_{12}$ specimens normalized against the not-aged condition tested at room temperature.

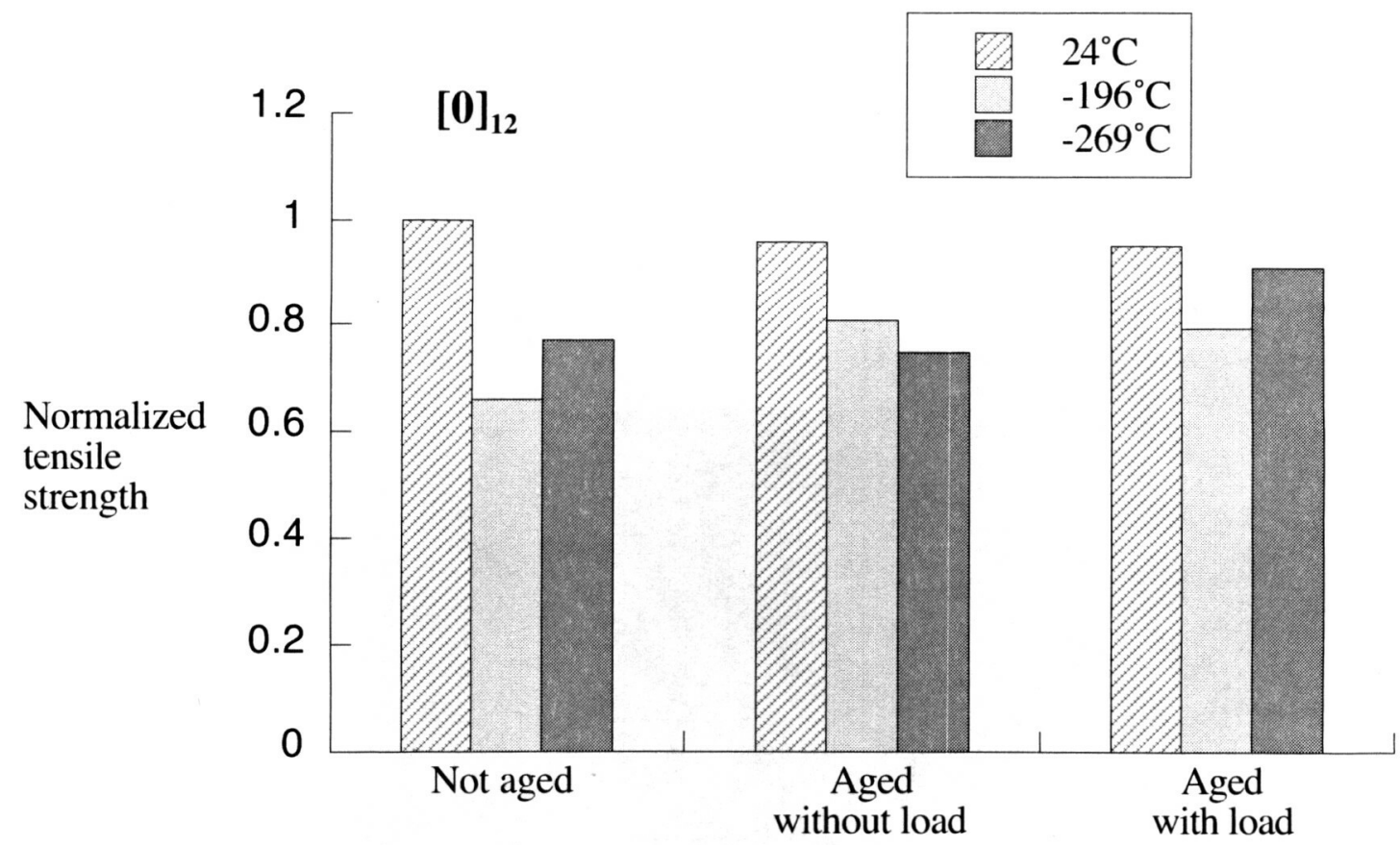

Figure 7 . Tensile strength of $[0]_{12}$ specimens normalized against the not-aged condition tested at room temperature. 


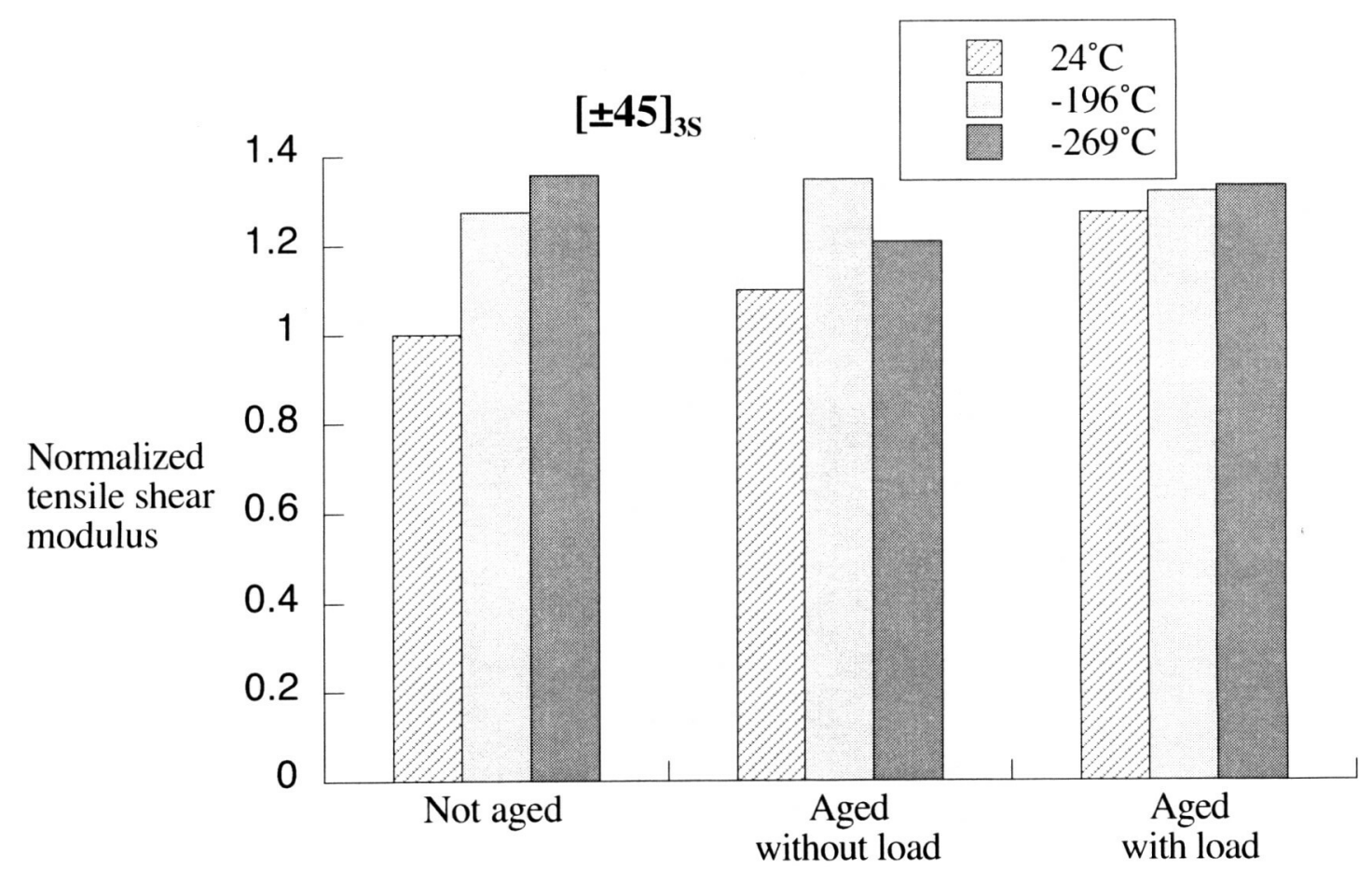

Figure 8. Shear tensile modulus of $[ \pm 45]_{3 \mathrm{~S}}$ specimens normalized against the not-aged condition tested at room temperature.

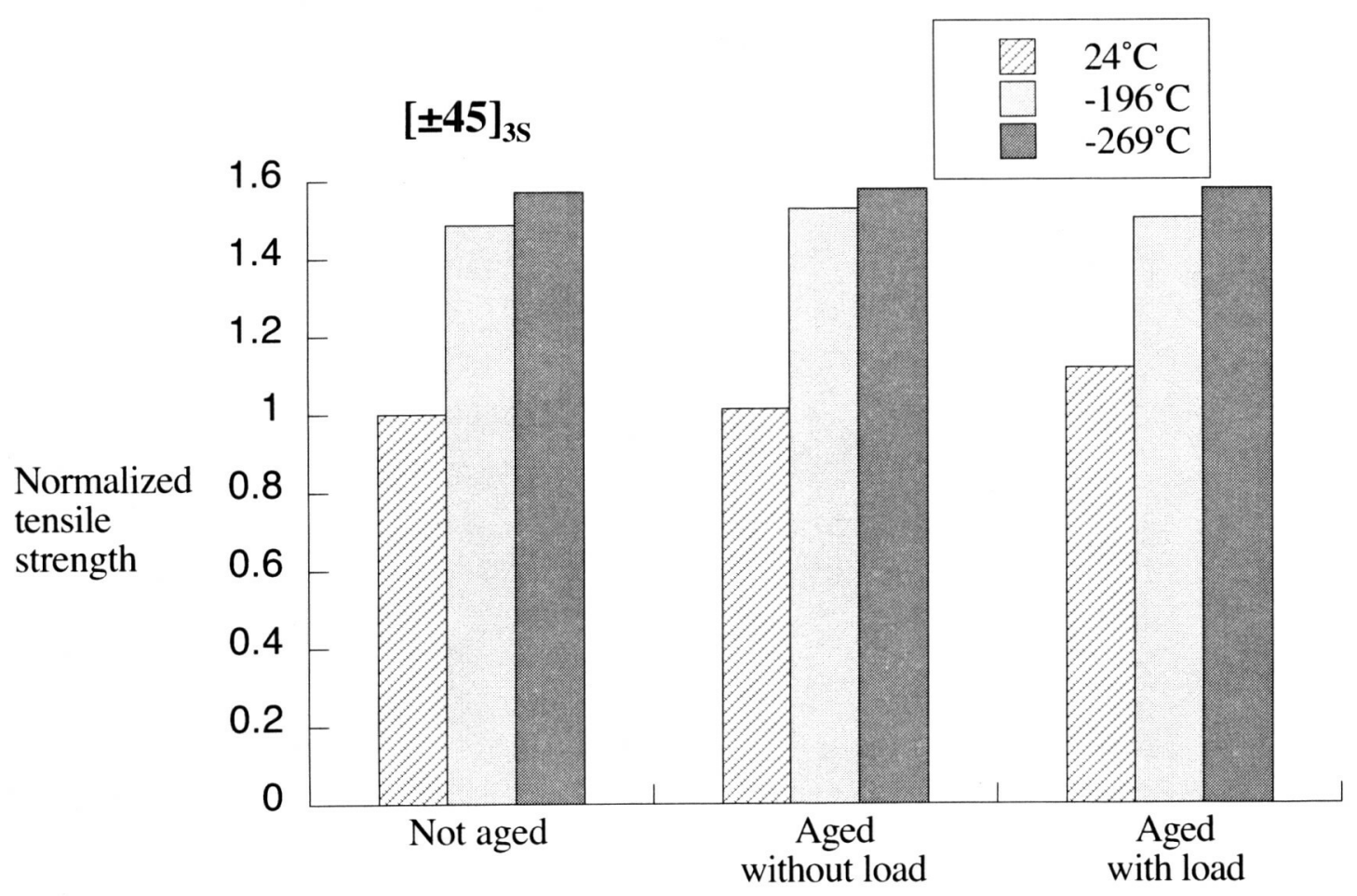

Figure 9. Tensile strength of $[ \pm 45]_{3 \mathrm{~S}}$ specimens normalized against the not-aged condition tested at room temperature. 


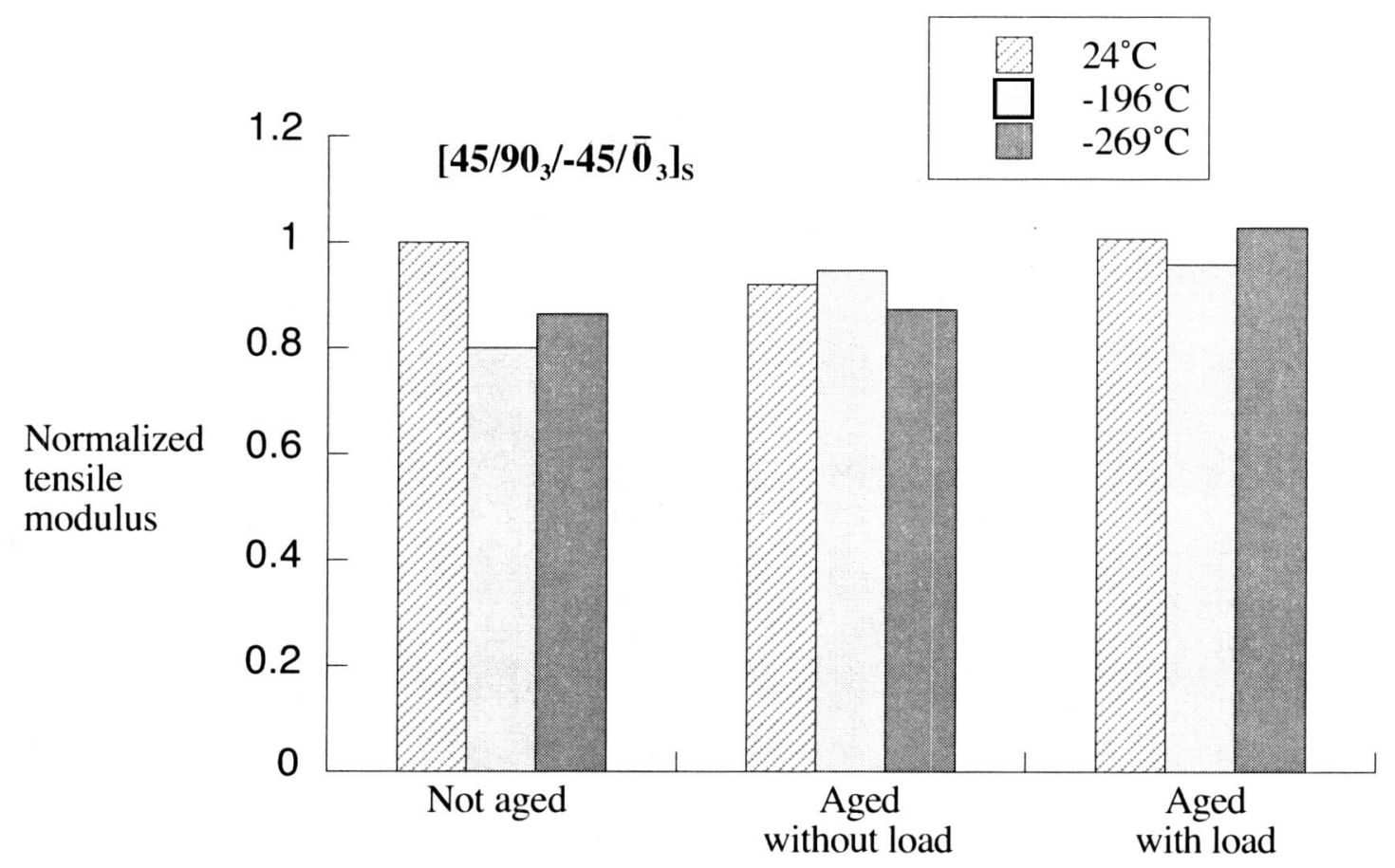

Figure 10. Tensile modulus of $\left[45 / 90_{3} /-45 / \overline{0}_{3}\right]_{S}$ specimens normalized against the not-aged condition tested at room temperature.

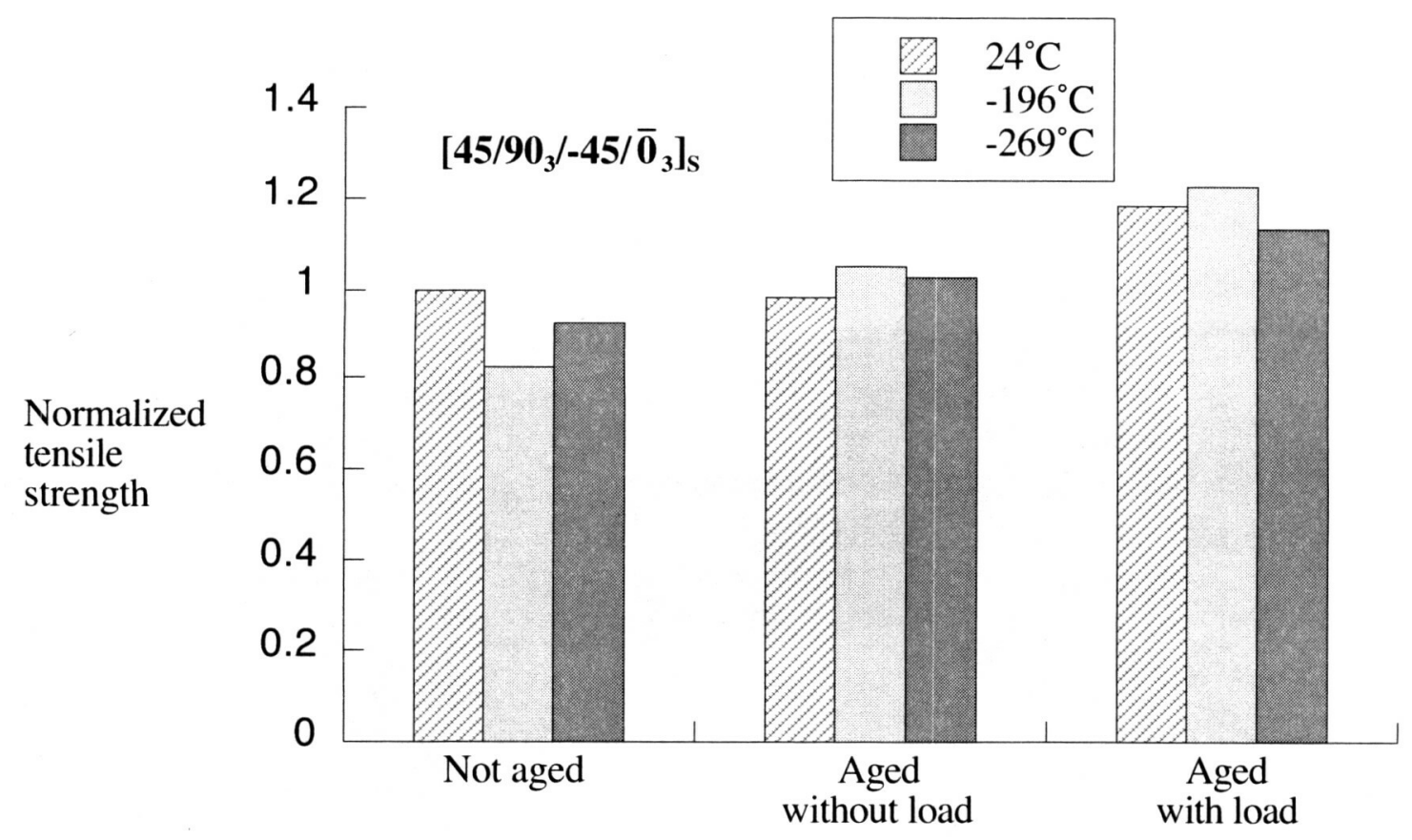

Figure 11. Tensile strength of $\left[45 / 90_{3} /-45 / \overline{0}_{3}\right]_{\mathrm{S}}$ specimens normalized against the not-aged condition tested at room temperature. 


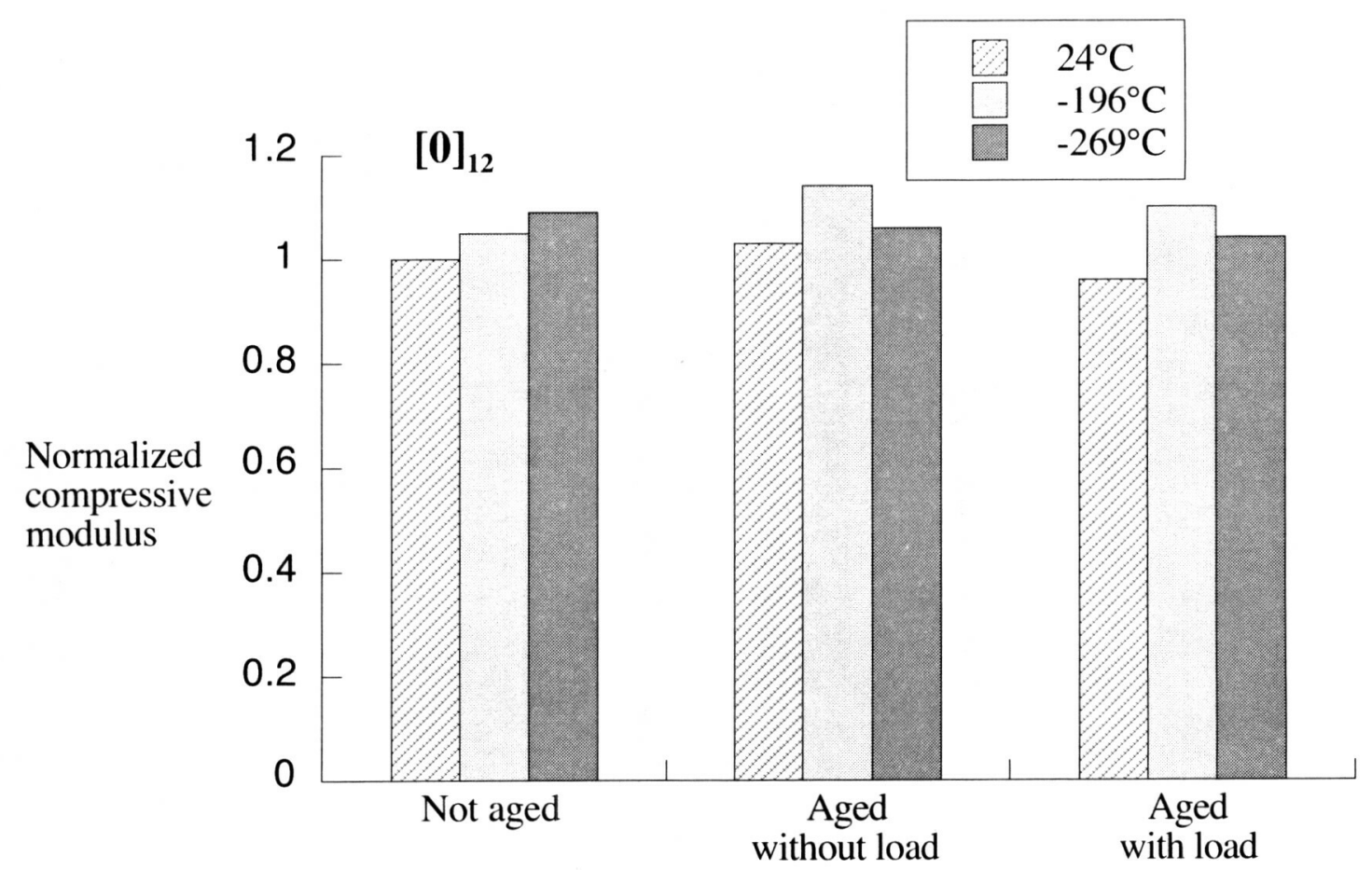

Figure 12. Compressive modulus of $[0]_{12}$ specimens normalized against the not-aged condition tested at room temperature.

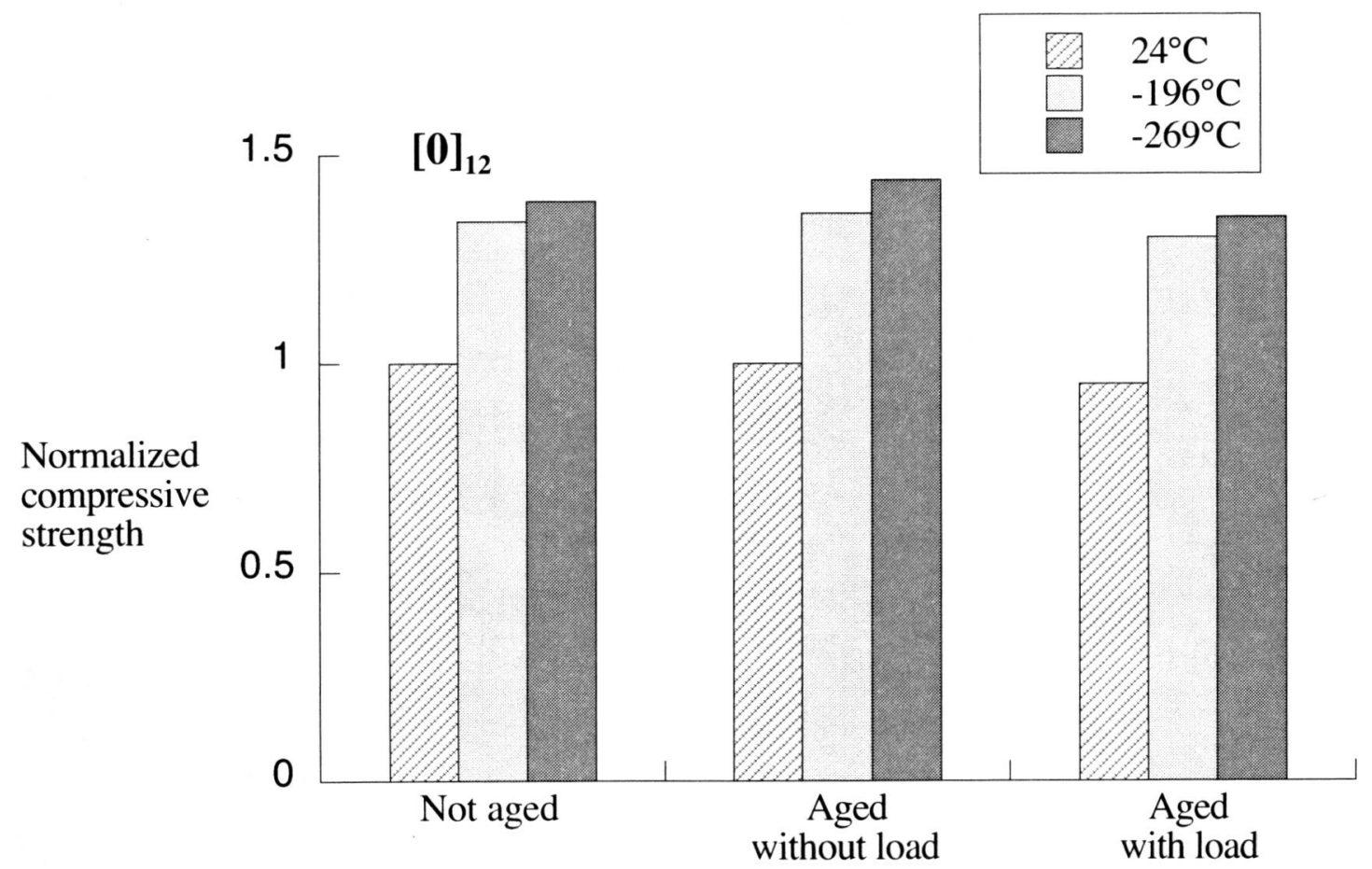

Figure 13. Compressive strength of $[0]_{12}$ specimens normalized against the not-aged condition tested at room temperature. 


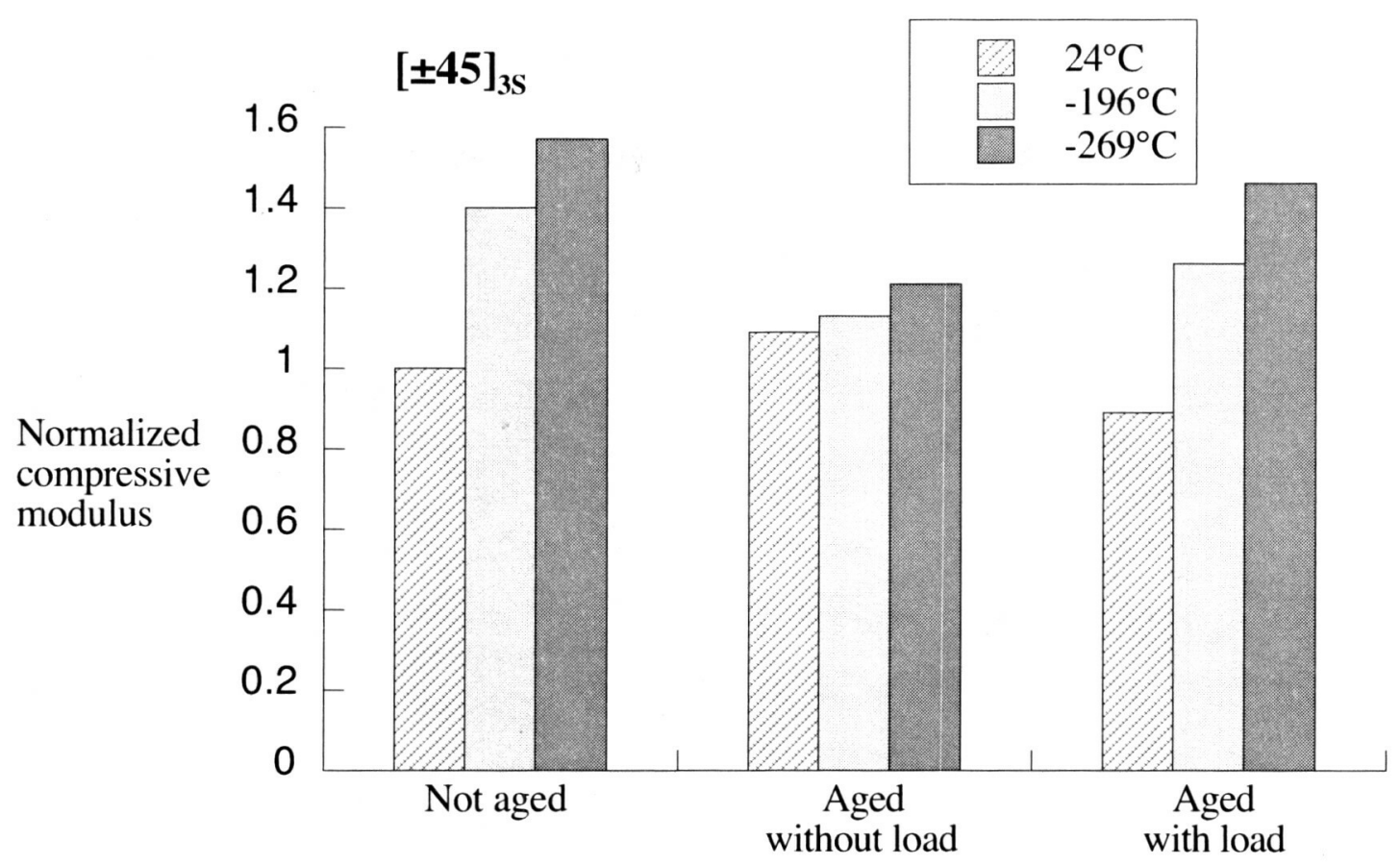

Figure 14. Compressive modulus of $[ \pm 45]_{3 \mathrm{~S}}$ specimens normalized against the not-aged condition tested at room temperature.

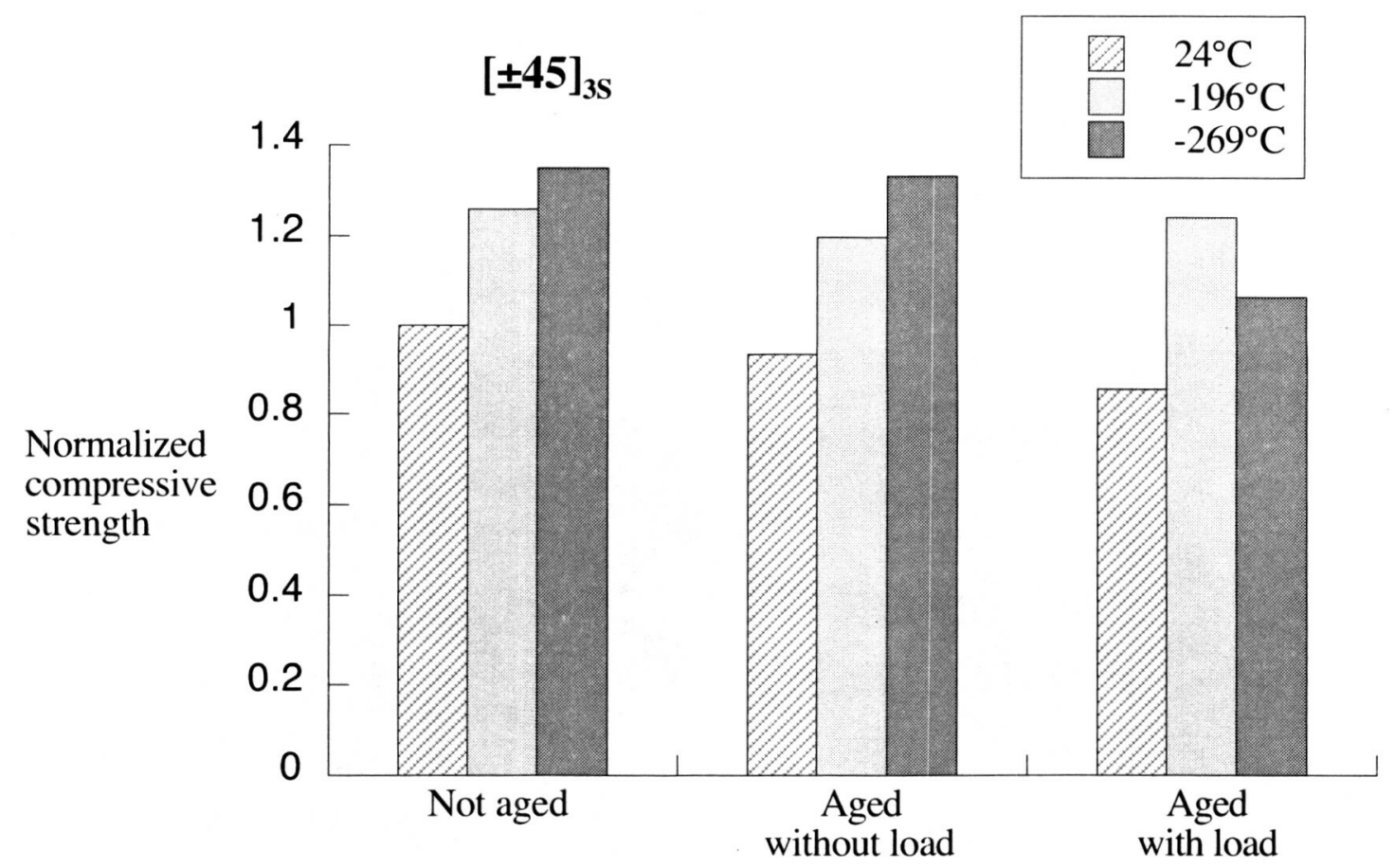

Figure 15. Compressive strength of $[ \pm 45]_{3 \mathrm{~S}}$ specimens normalized against the not-aged condition tested at room temperature. 


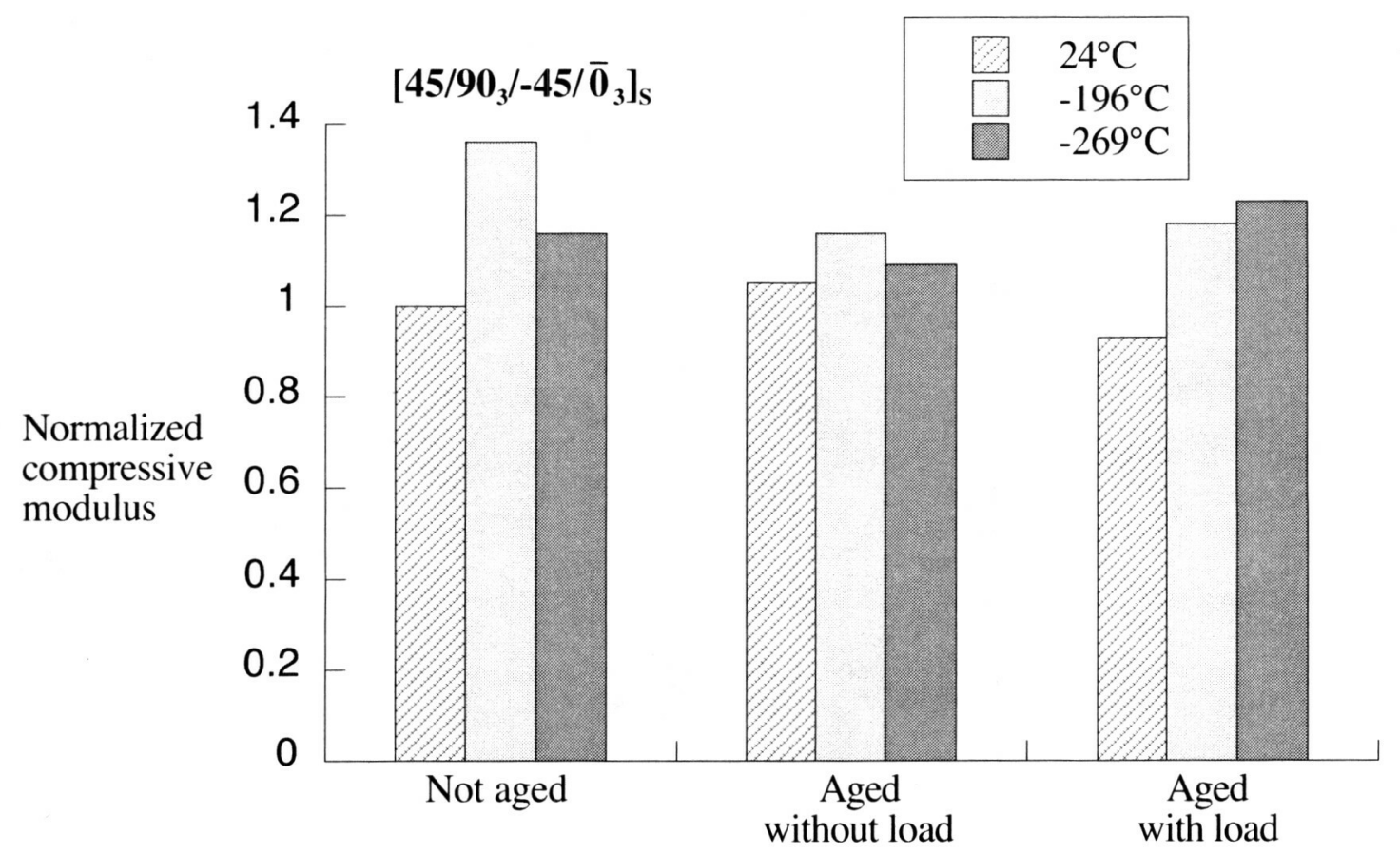

Figure 16. Compressive modulus of $\left[45 / 90_{3} /-45 / \overline{0}_{3}\right]_{\mathrm{S}}$ specimens normalized against the not-aged condition tested at room temperature.

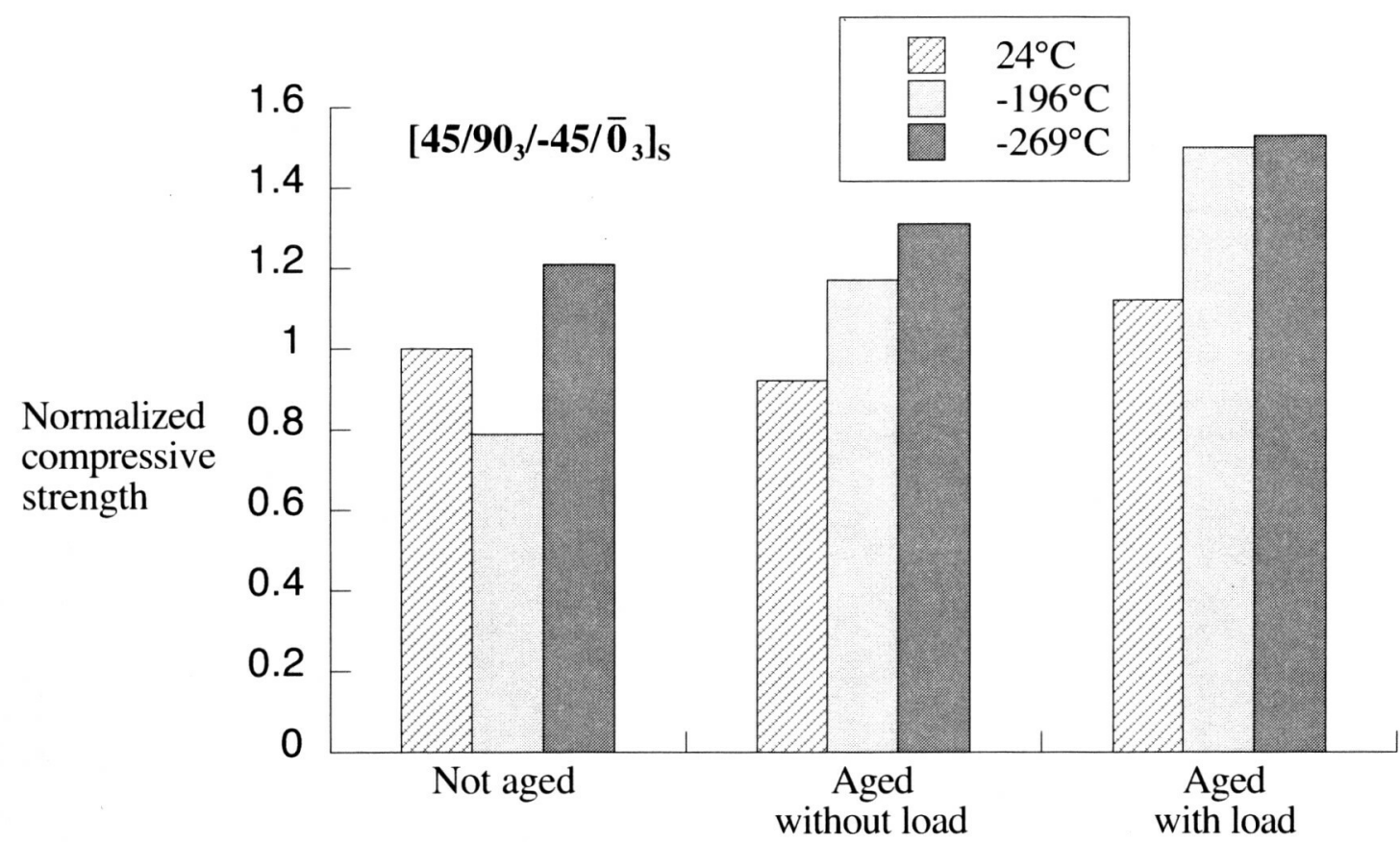

Figure 17. Compressive strength of $\left[45 / 90_{3} /-45 / \overline{0}_{3}\right]_{\mathrm{S}}$ specimens normalized against the not-aged condition tested at room temperature. 


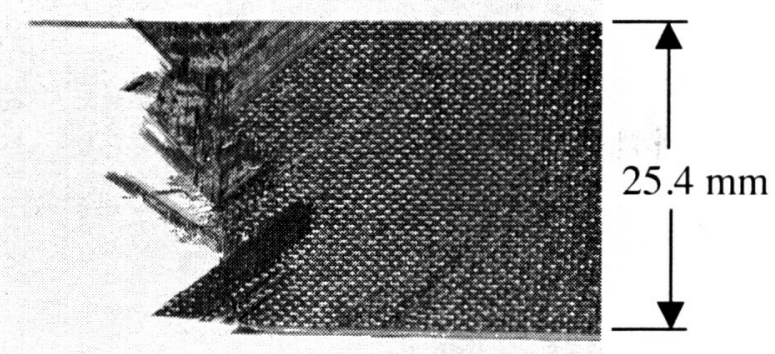

Figure 18. Fracture surface of a $\left[45 / 90_{3} /-45 / \overline{0}_{3}\right]_{S}$ laminate after tensile test at room temperature.

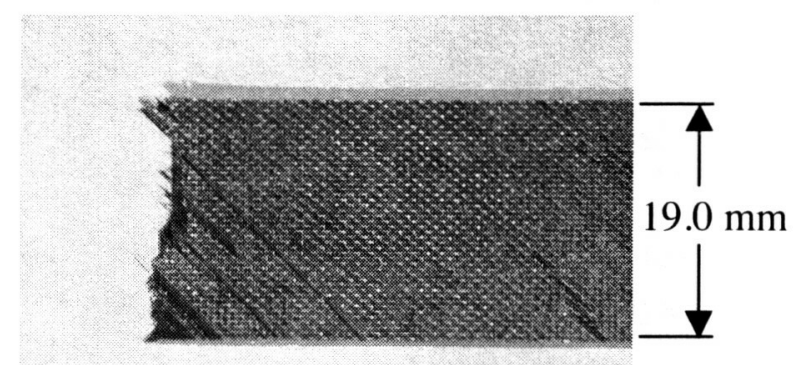

Figure 19. Fracture surface of a $\left[45 / 90_{3} /-45 / \overline{0}_{3}\right]_{\mathrm{S}}$ laminate after tensile test at $-196^{\circ} \mathrm{C}$.

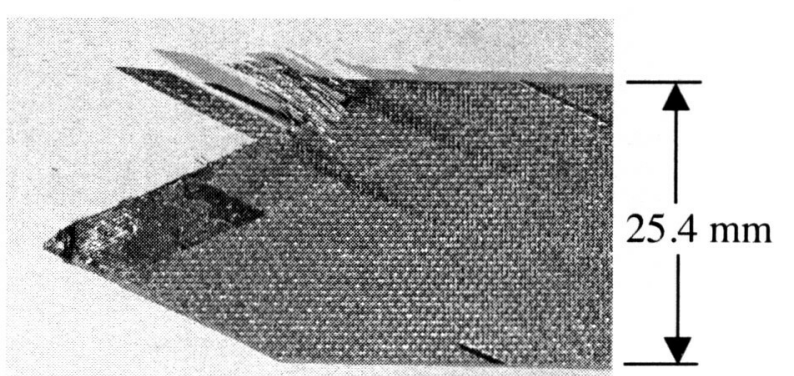

Figure 20. Fracture surface of a $[ \pm 25]_{3 \mathrm{~S}}$ laminate after tensile test at room temperature.

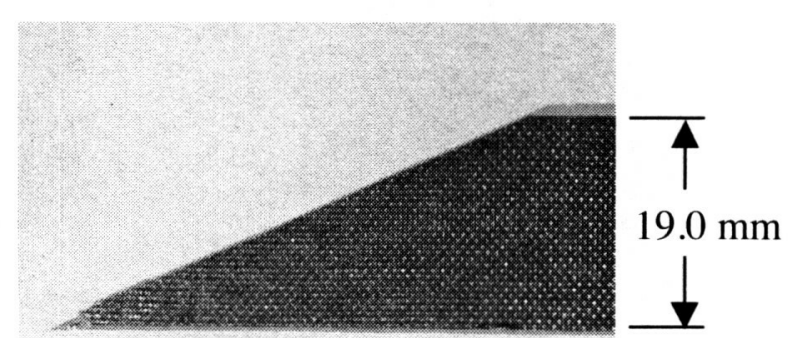

Figure 21 . Fracture surface of a $[ \pm 25]_{3 \mathrm{~S}}$ laminate after tensile test at $-196^{\circ} \mathrm{C}$. 


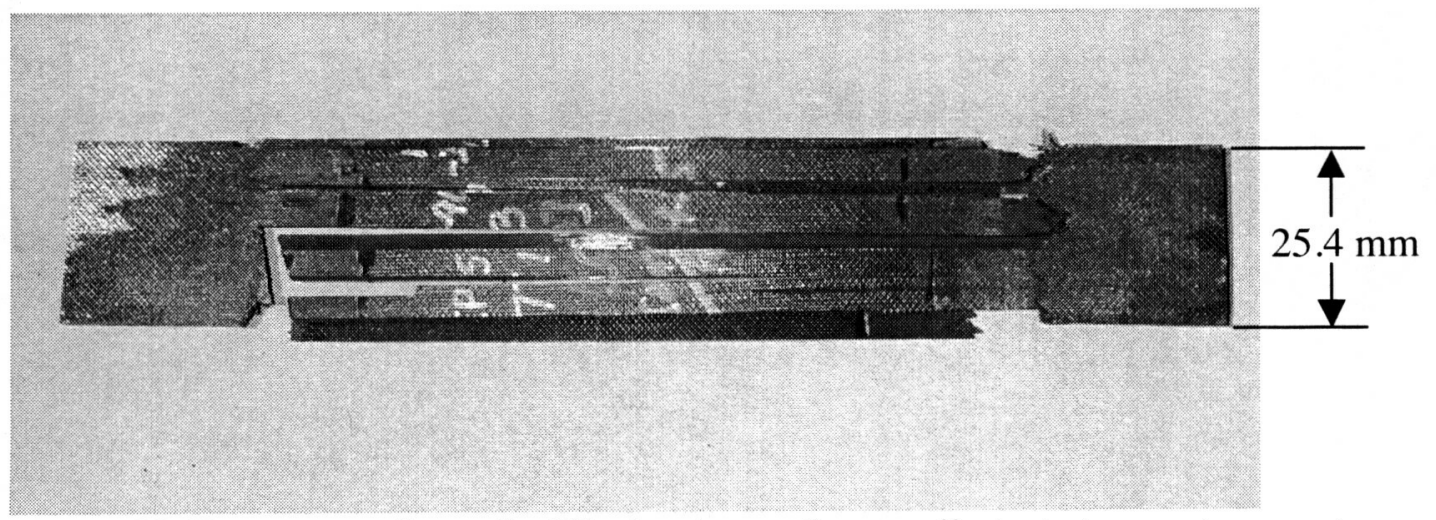

Figure 22. Fracture surface of a $[0]_{12}$ laminate after tensile test at room temperature.

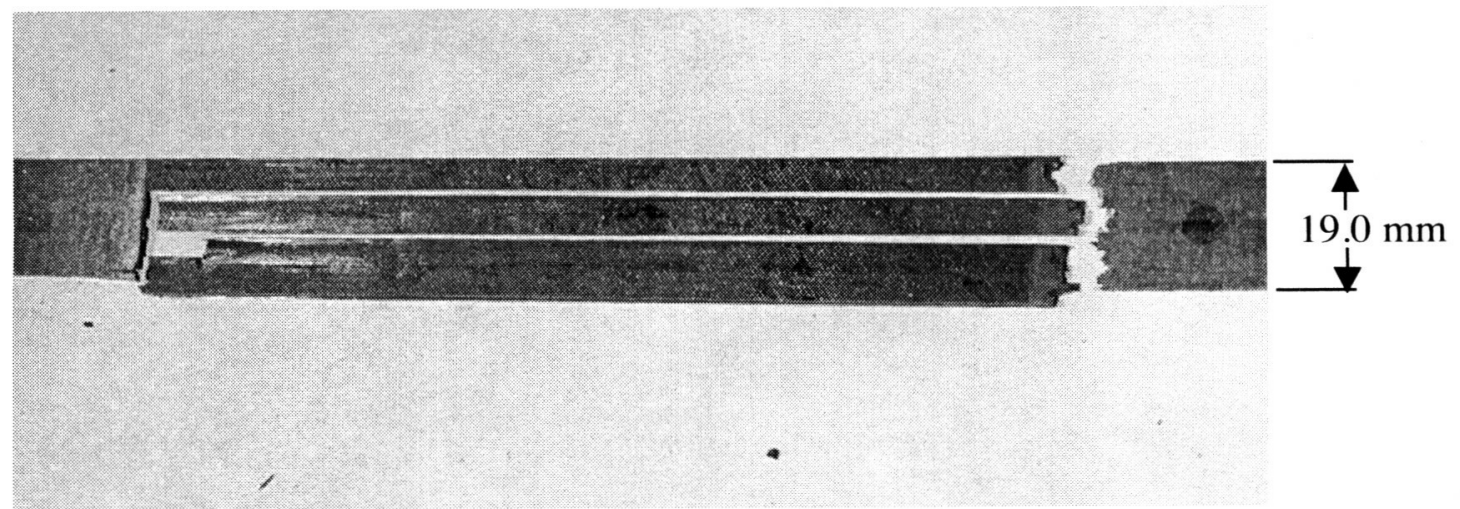

Figure 23. Fracture surface of a $[0]_{12}$ laminate after tensile test at $-196^{\circ} \mathrm{C}$.

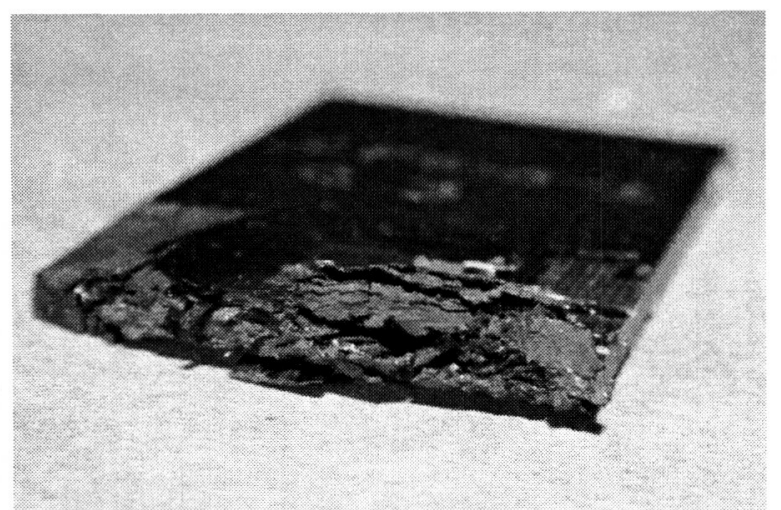

Figure 24. Fracture surface of $[0]_{12}$ laminate after compression test at room temperature. 


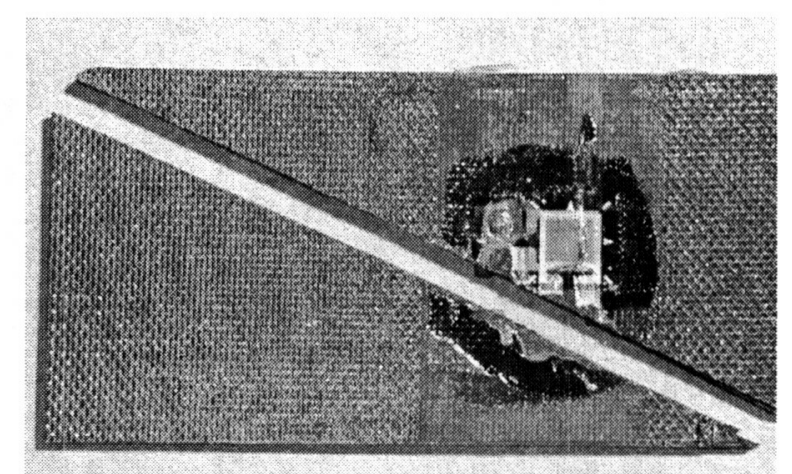

Figure 25 . Fracture surface of a $[ \pm 25]_{3 S}$ laminate after compression test at room temperature.
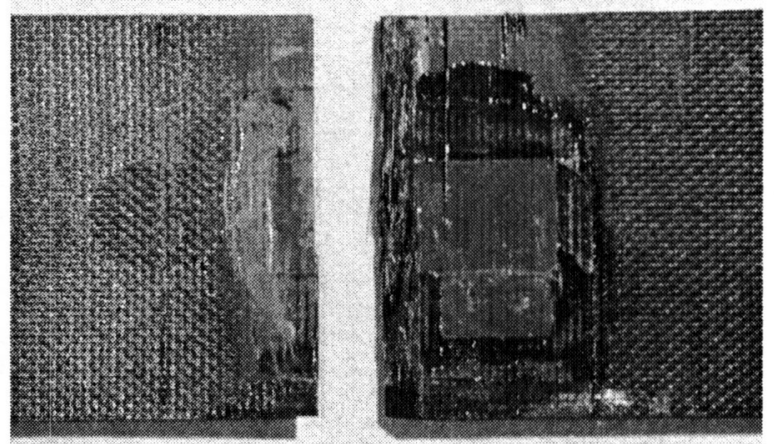

Figure 26. Fracture surface of a $[90]_{12}$ laminate after compression test at room temperature.

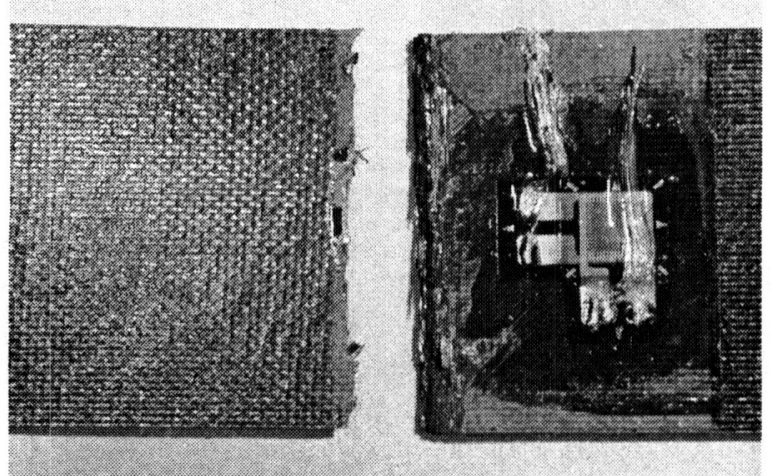

Figure 27. Fracture surface of a $\left[45 / 90_{3} /-45 / \overline{0}_{3}\right]_{S}$ laminate after compression test at room temperature. 


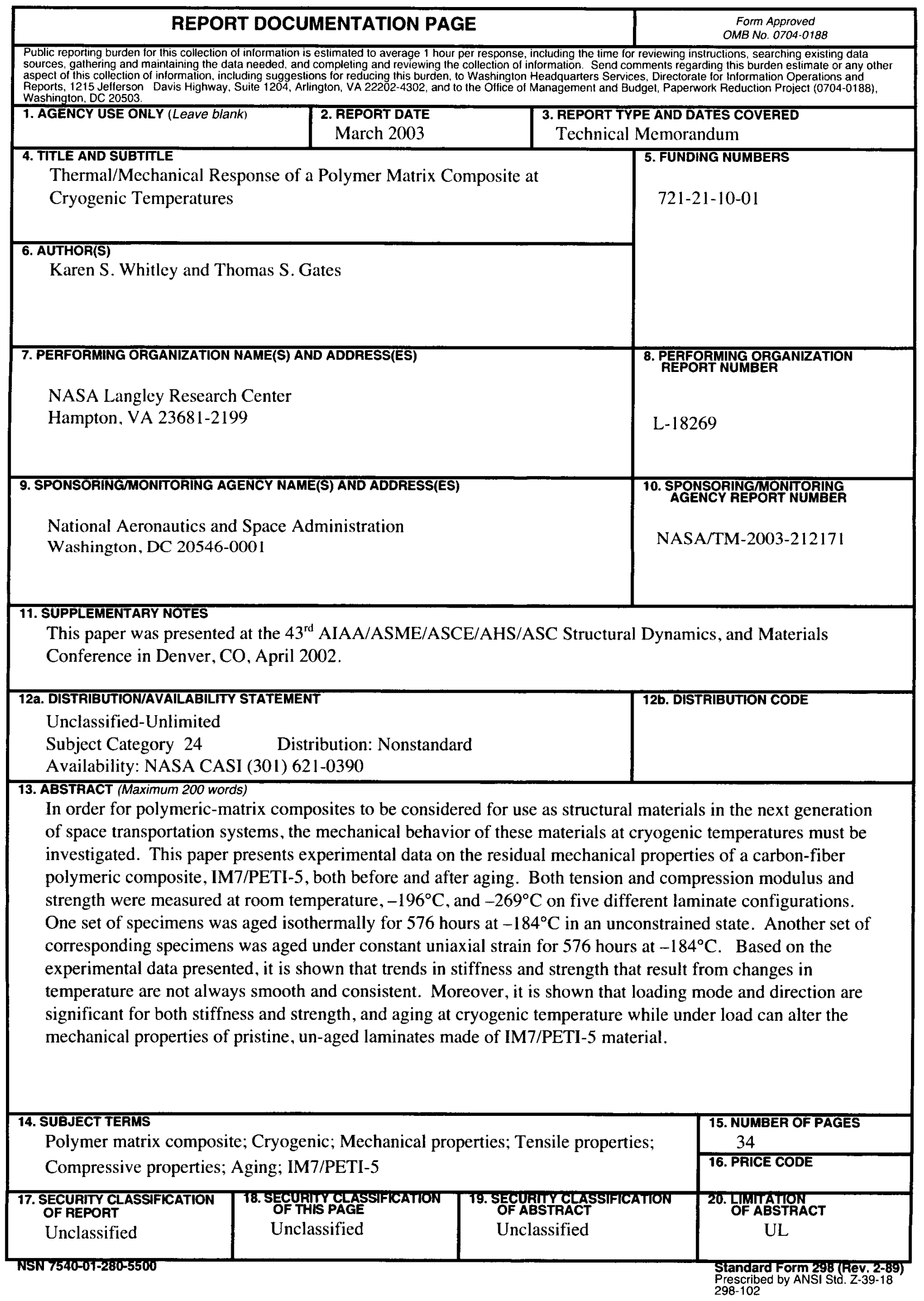

